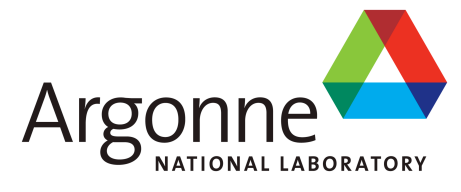

ANL-NE-11/35

Progress Report on Development of Intermediate Fidelity Full Assembly Analysis Methods

Nuclear Engineering Division 


\section{About Argonne National Laboratory}

Argonne is a U.S. Department of Energy laboratory managed by UChicago Argonne, LLC under contract DE-AC02-06CH11357. The Laboratory's main facility is outside Chicago, at 9700 South Cass Avenue, Argonne, Illinois 60439. For information about Argonne, see http://www.anl.gov.

\section{Availability of This Report}

This report is available, at no cost, at http://www.osti.gov/bridge. It is also available on paper to the U.S. Department of Energy and its contractors, for a processing fee, from:

U.S. Department of Energy

Office of Scientific and Technical Information

P.O. Box 62

Oak Ridge, TN 37831-0062

phone (865) 576-8401

fax (865) 576-5728

reports@adonis.osti.gov

\section{Disclaimer}

This report was prepared as an account of work sponsored by an agency of the United States Government. Neither the United States Government nor any agency thereof, nor UChicago Argonne, LLC, nor any of their employees or officers, makes any warranty, express or implied, or assumes any legal liability or responsibility for the accuracy, completeness, or usefulness of any information, apparatus, product, or process disclosed, or represents that its use would not infringe privately owned rights. Reference herein to any specific commercial product, process, or service by trade name, trademark, manufacturer, or otherwise, does not necessarily constitute or imply its endorsement, recommendation, or favoring by the United States Government or any agency thereof. The views and opinions of document authors expressed herein do not necessarily state or reflect those of the United States Government or any agency thereof, Argonne National Laboratory, or UChicago Argonne, LLC. 


\title{
Progress Report on Development of Intermediate
} Fidelity Full Assembly Analysis Methods

\author{
R. Hu and T. H. Fanning \\ Nuclear Engineering Division \\ Argonne National Laboratory
}

September 1, 2011 



\section{ABSTRACT}

While high fidelity modeling capabilities for various physics phenomena are being pursued under advanced modeling and simulation initiatives under the DOE Office of Nuclear Energy, they generally rely on high-performance computation facilities and are too expensive to be used for parameter-space exploration or design analysis. Onedimensional system codes have been used for a long time and have reached a degree of maturity, but limit their validity to specific applications. Thus, an intermediate fidelity (IF) modeling method is being pursued in this work for a fast-running, modest-fidelity, whole-core transient analyses capability. The new approach is essential for design scoping and engineering analyses and could lead to improvements in the design of the new generations of reactors and to the reduction of uncertainties in safety analysis.

This report summarizes the initial effort on the development of the intermediatefidelity full assembly modeling method. The requirements and the desired merits of the IF approach have been defined. A three-dimensional momentum source model has been developed to model the anisotropic flow in the wire-wrapped rod bundle without the need to resolve the geometric details. It has been confirmed that the momentum source model works well if its affecting region is accurately imposed. The validity of the model is further verified by mesh and parameter sensitivity studies. The developed momentum source model, in principle, can be applied to any wire-wrapped bundle geometries and any flow regimes; while the modeling strategy can be applied to other conditions with complex or distorted geometry, such as flow in blocked channels. 


\section{TABLE OF CONTENTS}

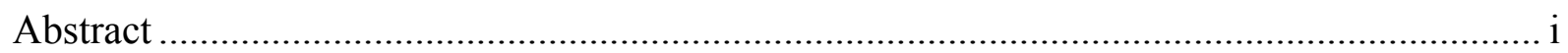

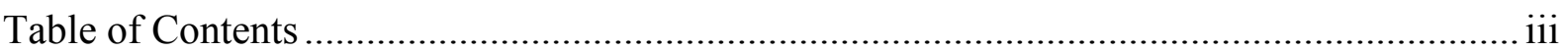

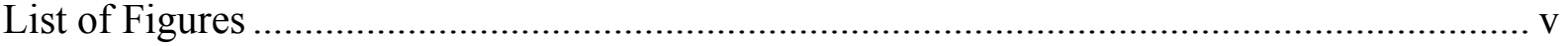

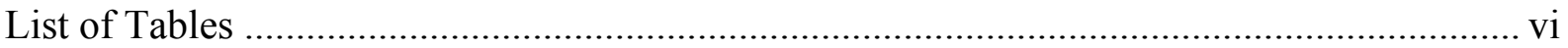

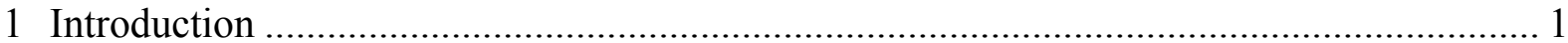

2 Requirements for the IF Modeling Method .................................................................... 2

3 Development of the 3D Momentum Source Model ...................................................... 3

3.1 The Three-Dimensional Momentum Source Model ................................................... 4

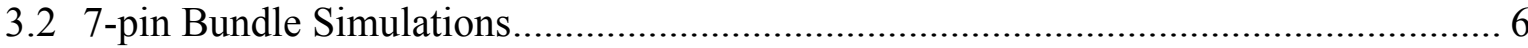

3.3 Mesh and Parameter Sensitivity Studies in 7-pin Bundle ..................................... 11

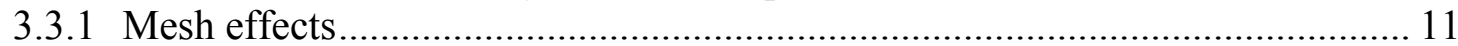

3.3.2 The effect of the tangential force................................................................ 13

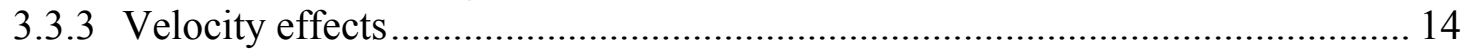

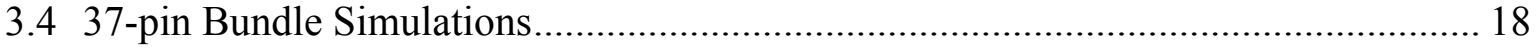

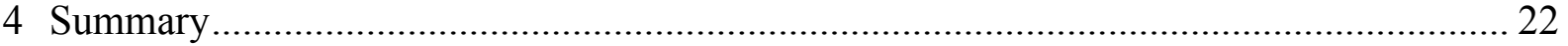

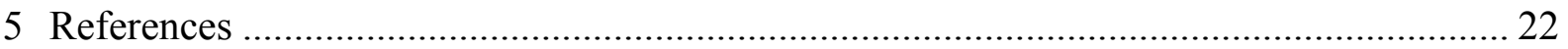




\section{LIST OF FIGURES}

Figure 1: Thermo-Fluid Dynamics modeling Hierarchy - Multi-Resolution Approach .............2

Figure 2: Sample spatial discretization schemes of the IF modeling Approach ..........................2

Figure 3: Various correlations for the mixing Stanton number[6].......................................... 3

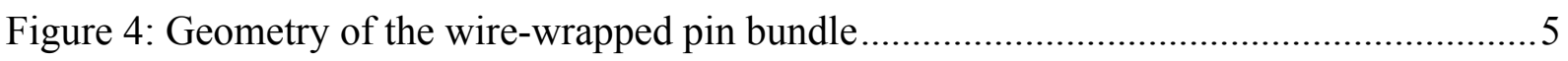

Figure 5: Illustration of minimum velocity gradient using velocity at cell center......................6

Figure 6: Mesh of a 7-pin bare bundle, wire surface conserved ............................................... 8

Figure 7: Lateral velocity distributions at the mid-span plane in 7-pin bundles......................... 8

Figure 8: Geometry of the 7-pin wire-wrapped pin bundle; cut lines indicate planes and plane groups used for cross-flow comparisons (group A: plane 1-6; group B: plane 7-12; group C: plane 13-18; group D: plane 19-24. ),....................................

Figure 9: Cross flow velocity distributions for planes in group A, wire-wrapped bundle .........9

Figure 10: Comparison of inter-subchannel cross flow velocities.........................................10

Figure 11: Momentum source distributions at $1 / 4$ span plane in a 7-pin bare bundle .................10

Figure 12: MS distributions at $1 / 4$ span plane in a 7-pin bare bundle, without wire

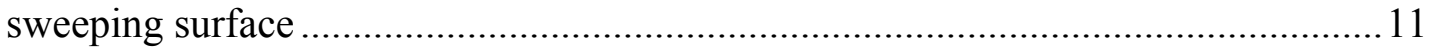

Figure 13: Inter-subchannel cross flow velocities, effects of wire sweeping surface................12

Figure 14: Inter-subchannel cross flow velocities, effects of mesh cell number .......................13

Figure 15: Inter-subchannel cross flow velocities, tangential force effect ............................... 14

Figure 16: Cross flow velocities in wire-wrapped bundle, model effects at $\mathrm{Re}=1120$ …......... 16

Figure 17: Cross flow velocities in wire-wrapped bundle, model effects of at $\mathrm{Re}=5600 \ldots \ldots \ldots .16$

Figure 18: Cross flow velocities in wire-wrapped bundle, effects of Reynolds number .......... 17

Figure 19: Cross flow velocities in wire-wrapped and B.B. with M.S. cases, velocity

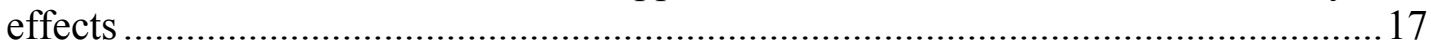

Figure 20: Mesh of a 37-pin wire-wrapped bundle in STAR-CCM+; cut lines indicate

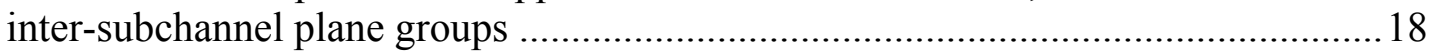

Figure 21: Averaged cross flow velocities in the 37-pin wire-wrapped bundle, inner plane groups.

Figure 22: Averaged cross flow velocities in the 37-pin wire-wrapped bundle, outer plane groups.

Figure 23: Mesh of a 37-pin bare bundle, wire surface conserved

Figure 24: Averaged cross flow velocities in the 37-pin bare bundle with MS, inner plane groups.

Figure 25: Averaged cross flow velocities in the 37-pin bare bundle with MS, outer plane groups

Figure 26: Inter-subchannel cross flow velocities in 37-pin bundles 


\section{LIST OF TABLES}

Table 1: Pressure drop comparison, effects of wire sweeping surface ................................. 12

Table 2: Pressure drop comparison, effects of mesh cell number ...................................... 13

Table 3: Pressure drop comparison among various momentum source models ..................... 14 


\section{Introduction}

Under the U.S. Department of Energy's Nuclear Energy Advanced Modeling and Simulation (NEAMS) Program, reactor integrated performance and safety codes (IPSC) are being developed within the SHARP framework.[1] High-fidelity, coupled neutron transport and thermal hydraulics capabilities are being developed to exploit advances in computers and software tools in order to facilitate reactor design optimization, provide increased assurance of performance and safety characteristics, and reduce the need for large scale integral experiments needed to characterize or validate reactor performance.

While the high fidelity modeling capabilities for various physics phenomena are being pursued, they generally rely on high-performance computation facilities and are too expensive to be used for parameter-space exploration or design analysis. Although one-dimensional system codes have been used for a long time and have reached a high degree of maturity, new computation tools towards multi-dimensional, multi-scale, multi-physics approaches could lead to improvements in the design of the new generations of reactors and to the reduction of uncertainties in safety analysis. Thus, an intermediate fidelity (IF) modeling method is being pursued to develop a fast-running, modest-fidelity, whole-core transient analyses capability.

To model the thermal-hydraulics behavior in fuel rod bundles, a multi-resolution approach is being pursued at Argonne National Laboratory. Within the multi-resolution framework, higher-resolution methods can serve as a validation tool and supply modeling parameters for lower-resolution methods, as shown in Figure 1, and lower-resolution method can supply boundary conditions to higher-resolution method in a coupled resolution simulation. Highresolution spectral Large Eddy Simulation (LES) methods are used to improve turbulence models for coarser resolution Reynolds-Averaged Navier-Stokes (RANS) based methods, and in turn, RANS simulations can be used to improve or extend correlations used in traditional sub-channel tools, or coupled with the existing tools to model the whole plant behavior while resolving the details of important components.

For wire-wrapped rod bundles, previous studies [2-4] showed that RANS-based methods can provide accurate hydrodynamic predictions but are limited by their capability to characterize long-term transients or large system simulations; and that traditional sub-channel tools can provide whole-plant transient response but cannot resolve the details of the anisotropic velocity distribution due to the wire-wrap sweeping. Thus, the IF modeling method aims at an intermediate-resolution modeling approach to fill the gap between the RANS-based method and the traditional sub-channel method. The objective is to develop scalable intermediate-resolution assembly modeling methods to support full-core transient modeling when coupled to existing or emerging neutronics and fuel performance models.

This report summarizes the initial effort of the ongoing work, which encompasses two major activities: defining the requirements or the desired merits of the IF modeling method, and developing the methodology to model the anisotropic flow in a complex flow channel with relatively coarse spatial discretization which does not resolve all the geometric details. 

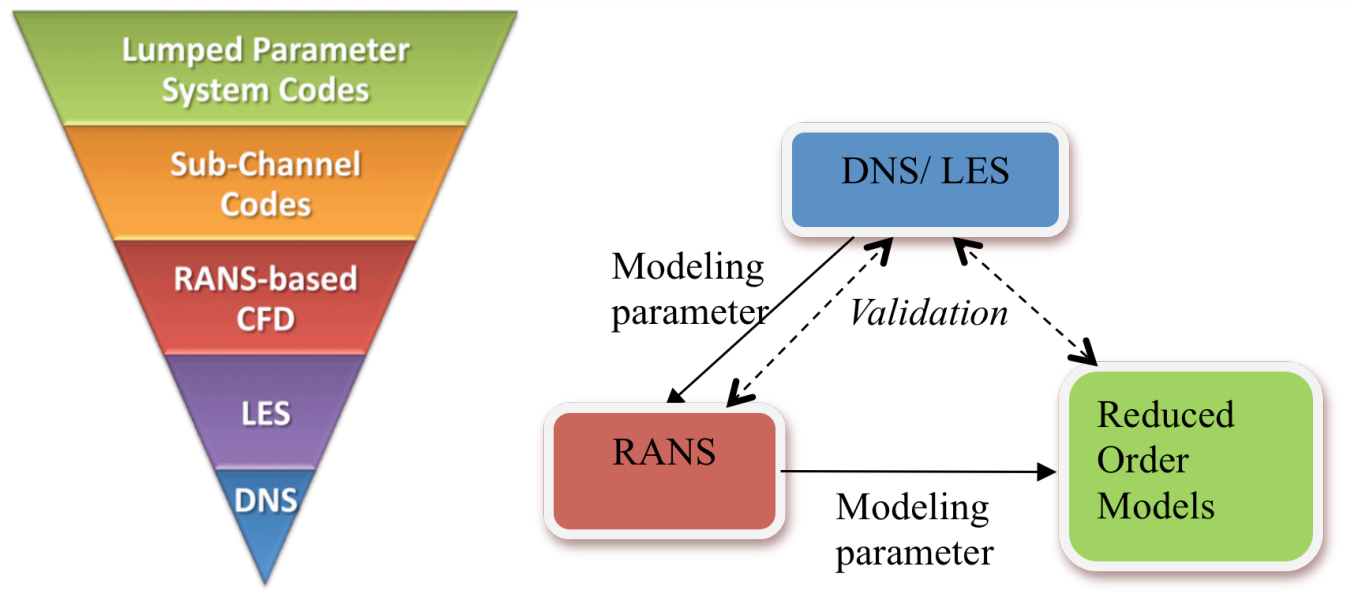

Figure 1: Thermo-Fluid Dynamics modeling Hierarchy - Multi-Resolution Approach

\section{Requirements for the IF Modeling Method}

The IF method for thermal-hydraulics modeling in the fuel assembly is being developed to fill the gap between CFD methods and traditional sub-channel methods, which requires modest resolution and improved models in reduced-order methods.

The spatial discretization of the IF method should represent the local heterogeneity explicitly at sub-pin and sub-subchannel level to allow integrated simulation of neutronic, thermal-hydraulic, and thermo-mechanical phenomena. It could utilize existing meshing tools such as CUBIT[5] to generate scalable or adaptive mesh. For coolant region in a reactor rod bundle geometry, the discretization scheme in Figure 2 is of interest since it could divide a sub-channel into 3 (or 6) identical cells in a triangle lattice, and 4 (or 8) identical cells in a square lattice.

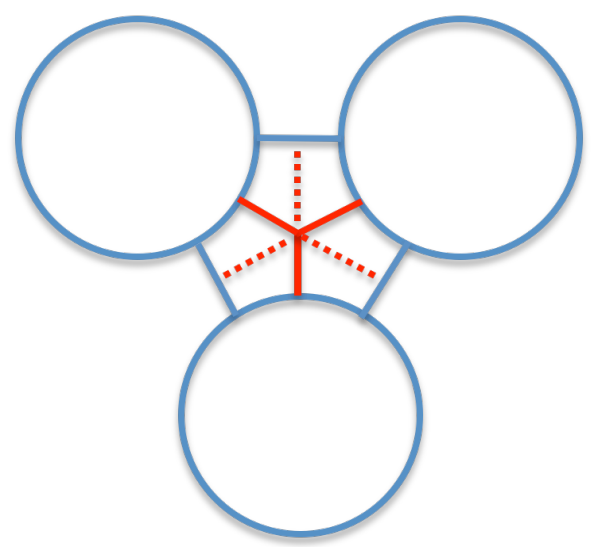

(a) triangle lattice

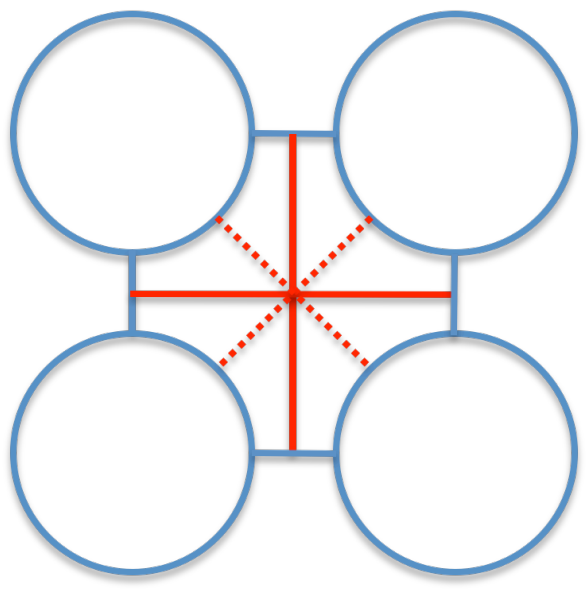

(b) square lattice

Figure 2: Sample spatial discretization schemes of the IF modeling Approach

The IF modeling method will also improve the empirical models and correlations incorporated in the existing system and sub-channel analysis codes which limit their validity to specific applications. Due to the large uncertainties and discrepancies among various correlations in the literature, the cross-flow and the turbulent mixing models in the rod 
bundles are of primary interest in this work. As shown in Figure 3[6], large discrepancies were found among various correlations for the mixing Stanton number. It is highly dependent on the channel geometry yet many existing correlation are geometry independent.

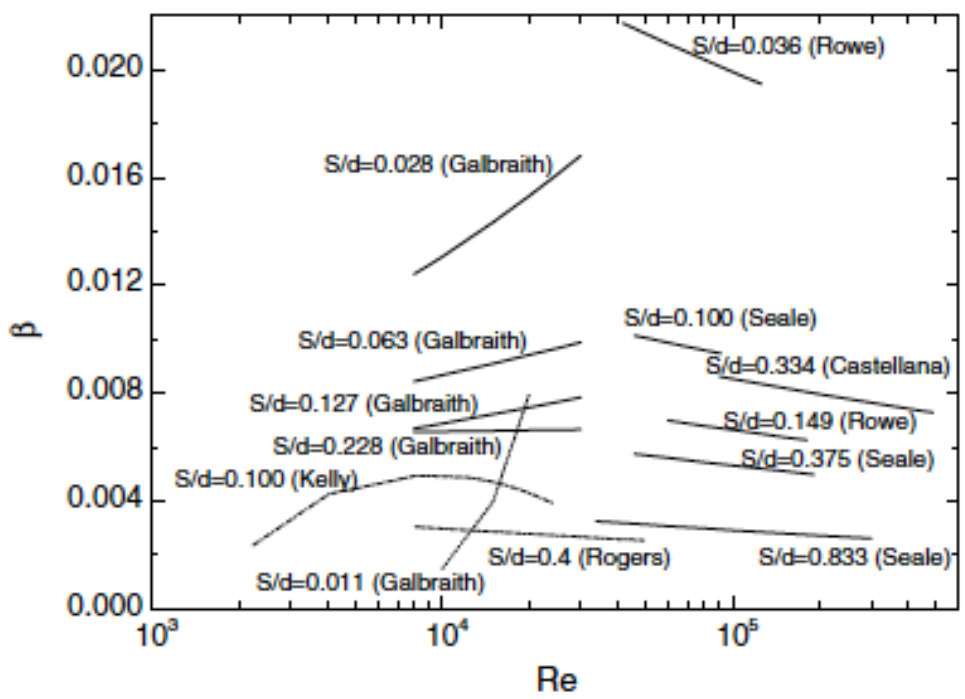

Figure 3: Various correlations for the mixing Stanton number[6]

Other desired merits of the IF modeling method include:

1) Relying on available frameworks or tools to reduce the development workload. It will be developed under the MOAB[7] framework to allow convenient multi-physics integration with other tools being developed within the Reactor and Fuels IPSC; CUBIT could be used for mesh generation; and PETSc[8] could be utilized in the solver development.

2) Parallel implementation to allow execution in high performance computers for fullcore transient simulations.

3) High flexibility to be coupled with existing system analysis tools and CFD tools, or coupled with neutronics or thermo-mechanical codes, for multi-scale multi-physics simulations.

The requirements and desired merits of the IF modeling method have thus been defined. The initial work was then devoted for the thermal-hydraulics modeling of wire-wrapped rod bundles, as described in the following section. A three-dimensional momentum source model has been developed to model the anisotropic flow in the wire-wrapped rod bundle. While the developed model is specific for a wire-wrapped rod bundle, the methodology is suitable for flow channels with complex geometry, such as deformed channels resulting from rod bowing or ballooning.

\section{Development of the 3D Momentum Source Model}

Modeling the flow in the analysis of wire-wrapped rod bundles is still a challenging problem. Large uncertainties exist in the treatment of wire-spacers and drag models in the 
momentum transfer of current low-resolution (lumped parameter) models. Some traditional subchannel codes, such as SAS4A/SASSYS-1[9] and SUPERENERGY-2[10], treat the wire effects as solely enhancement of turbulent mixing but ignore the directional cross flow between subchannels. Others, such as COBRA-4[11], ASFRE[12], and MATRA-LMRFB[13], apply "forcing function" type models to account for the diversion flow but are limited in their applications to certain validated conditions (flow regime, channel geometry, or operating conditions) and rely on complex coefficients which were derived from fitting certain sets of experimental data.

Recently, Computational Fluid Dynamics (CFD) simulations of wire-wrapped rod bundles have received extensive interest. This includes the work[2-4] preceding this work, as well as the work of Hamman and Berry[14], Gajapathy et al.[15], and Natesan et al.[16] who used RANS-based simulations to study geometries ranging from 7-pin to 217-pin configurations. However, the CFD simulations are still limited in their capability to characterize long-term transients or large system simulations.

As part of the ongoing effort to pursue an intermediate-fidelity modeling capability for pin-bundle thermal-hydraulics and to fill the gap between RANS-based methods and traditional sub-channel methods, a three-dimensional momentum source term that spirals around each rod is introduced to characterize the wire-wrap effects on the hydraulics in the rod bundle. The wire-wrapped rod bundle can then be simulated using a bare-bundle geometry. A separate effort has been initiated for modeling the natural turbulent mixing due to velocity fluctuations.[17] The momentum source model was examined in both 7-pin and 37-pin configurations using the commercial CFD code STAR-CCM+[18]. Simulation results were compared between the reference wire-wrapped bundles and bare-bundles with extra momentum sources. The validity of the model is further confirmed by mesh and parameter sensitivity studies.

\subsection{The Three-Dimensional Momentum Source Model}

To account for the wire geometry, a three-dimensional momentum source (MS) model is derived from momentum conservation and is dependent on local velocity profiles. The momentum source is represented as a body force within the volume previously occupied by the wire-wrap. It is decomposed into three directions: normal to the wire and tangential to the pin $n_{n}$, along to the wire $n_{t}$, and normal to the pin and wire $n_{p t}$. The forces in the normal directions are to block the flow, while the force in the wire tangential direction is assumed to introduce additional friction:

$$
\vec{f}=\vec{f}_{n}+\vec{f}_{t}+\vec{f}_{p n}
$$

The Navier-Stokes momentum conservation equation for an incompressible fluid is considered:

In the wire normal direction,

$$
\rho \frac{D \vec{v}}{D t}=-\nabla p+\mu \nabla^{2} \vec{v}+\vec{f}
$$




$$
\frac{D v_{n}}{D t}=\frac{\partial v_{n}}{\partial t}+v_{n} \frac{\partial v_{n}}{\partial n_{n}}+v_{t} \frac{\partial v_{n}}{\partial n_{t}}+v_{p n} \frac{\partial v_{n}}{\partial n_{p n}}
$$

Assuming that the introduced body force is the dominant contributor to change the momentum of the fluid in the wire normal direction and neglecting the time-dependent term, we can obtain

$$
f_{n}=\left(\rho v_{n} \frac{\partial v_{n}}{\partial n_{n}}+\rho v_{t} \frac{\partial v_{n}}{\partial n_{t}}+\rho v_{p n} \frac{\partial v_{n}}{\partial n_{p n}}\right) \cdot\left(-\vec{n}_{n}\right)
$$

where

$$
\begin{aligned}
& \vec{n}_{n}=[\cos \varphi \cdot \cos (\theta-\pi / 2), \cos \varphi \cdot \sin (\theta-\pi / 2), \cos \varphi], \text { wire normal direction; } \\
& \vec{n}_{t}=[\sin \varphi \cdot \cos (\theta+\pi / 2), \sin \varphi \cdot \sin (\theta+\pi / 2), \cos \varphi], \text { wire tangential direction; } \\
& \overrightarrow{n_{p n}}=[\cos \theta, \sin \theta, 0], \text { direction normal to both the pin and the wire. }
\end{aligned}
$$

The above normal vectors and the angles, $\theta=2 \pi z / H$ and $\varphi=a \tan \left(\pi\left(D+d_{w}\right) / H\right)$ are shown in Figure 4, where $D$ is the pin diameter, $d_{w}$ is the wire wrap diameter, and $H$ is the wire wrap lead length. The velocity vectors are then $v_{n}=V \cdot \overrightarrow{n_{n}} ; v_{t}=V \cdot \overrightarrow{n_{n}} ; v_{p n}=V \cdot \overrightarrow{n_{p n}}$.
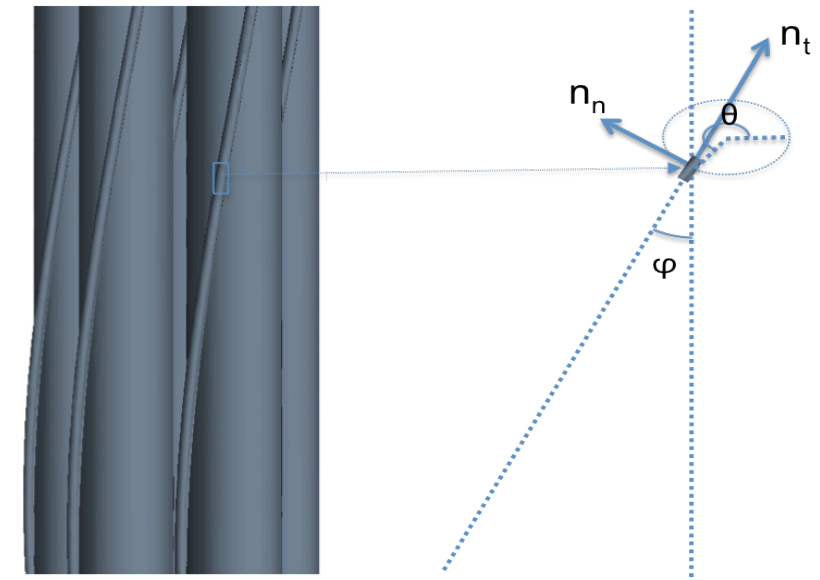

Figure 4: Geometry of the wire-wrapped pin bundle

Given the $[x, y, z]$ coordinates of each mesh cell, the body force will be applied only to the region previously occupied by the wire: $d=\sqrt{\left(x-x_{w}\right)^{2}+\left(y-y_{w}\right)^{2}} \leq r_{w}=d_{w} / 2$, where the coordinate of the center of the wire, $\left[x_{w}, y_{w}, z_{w}\right]$, relative to the center of the bottom surface of the pin are defined in the following parametric equations in which $t$ is in the range 0 to $2 \pi$.

$$
\left\{\begin{array}{l}
x_{w}=\left(R+r_{w}\right) \cos (t) \\
y_{w}=\left(R+r_{w}\right) \sin (t) \\
z_{w}=\frac{H}{2 \pi} \cdot t
\end{array}\right.
$$

It is seen from Eq. (3) that the introduced force should be dependent on local velocity gradient caused by the existence of the wire. The above M.S. model was examined with the 
CFD software STAR-CCM+. Due to a limitation that only cell center velocity is available, the velocity gradients were assumed proportional to the cell center velocity in the normal directions. Assuming $\partial v_{n} / \partial n_{n}=C v_{n} / d_{w}, \partial v_{n} / \partial n_{t}=C v_{n} /\left(d_{w} / \cos \varphi\right)$, and $\partial v_{n} / \partial n_{p n}=C v_{n} / d_{w}$, we obtain:

$$
f_{n}=\frac{C \rho v_{n}\left(v_{n}+v_{t} \cos \varphi+v_{p n}\right)}{d_{w}} \cdot\left(-\overrightarrow{n_{n}}\right),
$$

where $C$ is a multiplication coefficient. Since the fluid cannot flow through the wire, the velocity gradient should be large enough to block the flow in the directions normal to the wire. Thus, $C$ should be larger than two, as illustrated in Figure 5.

Similarly, we can obtain

$$
f_{p n}=\frac{C \rho v_{p n}\left(v_{n}+v_{t} \cos \varphi+v_{p n}\right)}{d_{w}} \cdot\left(-\vec{n}_{p n}\right) .
$$

For the force in the wire tangential direction, a general form of friction force is assumed:

$$
f_{t}=\frac{f_{f r} \rho v_{t}^{2}}{2 d_{w}} \cdot\left(-\overrightarrow{n_{t}}\right),
$$

in which $f_{f r}$ is the friction factor. For simplicity, the Blasius-McAdams correlation [19] for tube flow is used in this work. Later, the effects of the tangential force on flow distribution and pressure drop will be discussed.

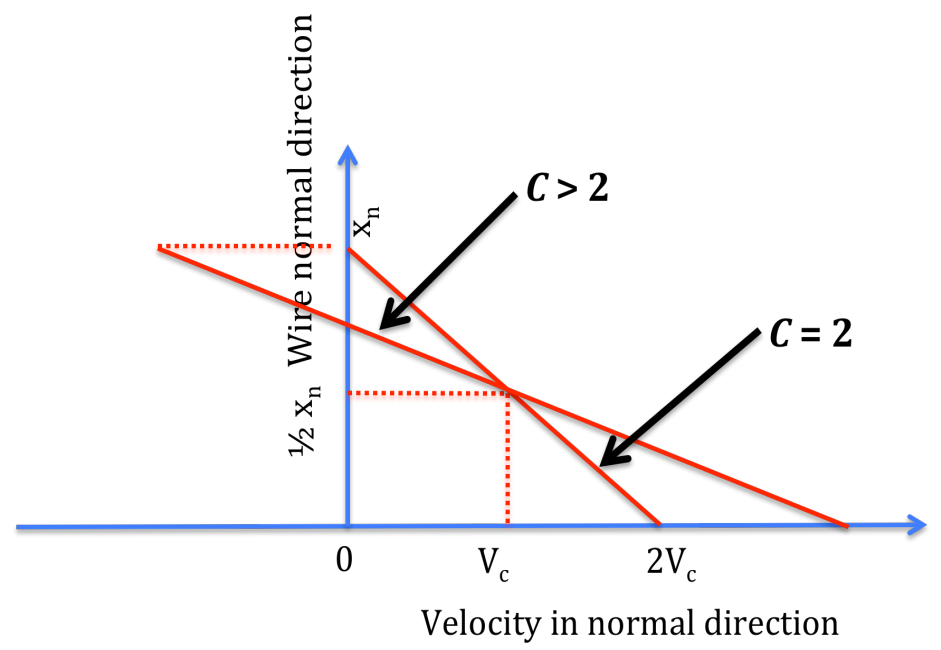

Figure 5: Illustration of minimum velocity gradient using velocity at cell center

\subsection{7-pin Bundle Simulations}

The momentum source model was first examined in a 7-pin bundle configuration using the commercial CFD software STAR-CCM+. Star-CCM+ supports the use of generic polyhedral mesh elements, greatly simplifying the generation of computational meshes for complex geometries. All simulations presented herein are steady state RANS-based simulations using the realizable $k-\varepsilon$ turbulence model and the two-layer all-y+ wall formulation[18]. The SIMPLE predictor-corrector algorithm was used. Evaluations of 
sensitivities of predictions for 7-pin wire-wrapped fuel assemblies to computational mesh density, RANS turbulence model formulation, boundary flow conditioning, and comparisons to Large Eddy Simulations (LES) have been previously discussed in references [2] and [3]. It is confirmed that RANS-based simulations can provide acceptably accurate hydrodynamic predictions in the wire-wrapped bundle geometry.

Hydrodynamics inside a bare bundle is simulated to examine the impact of the momentum source model in which additional momentum sources were applied as described above. In STAR-CCM+, only cell centroids (coordinates at geometric center) are known. Thus, if the cell centroid is inside the wire, the whole cell is considered to be inside the momentum source affecting region. To obtain an accurate MS affecting region, an in-place interface for the wire surface was added in the STAR-CCM+ model, as shown in Figure 6. Later, the effects of this modeling approximation will be examined.

The predicted lateral flow velocity distribution at the span outlet is shown in Figure 7, along with that of the wire-wrapped bundle case. The cross-flow distribution and magnitude are very similar for the two cases, except the abnormal high cross flow rate in the upstream of the wire and the high bouncing cross flow away from the wire, which is underestimated in the bare bundle with momentum source case. To facilitate the comparison between different simulations, average cross-flow velocities (normalized to the inlet velocity) were calculated as a function of axial position along four groups of inter-subchannel cut planes shown in Figure 8 .

For the wire-wrapped pin bundle, the cross flow velocity distributions for planes in group A are shown in Figure 9. Almost identical profiles are obtained for each plane in the group. If shifting them to the same phase, they will overlap each other. The same symmetry exists in the other groups, as well as in the plane groups in the bare bundle case. The results of these inter-subchannel cross-flow velocities for different plane groups (after shifting and averaging) are shown in Figure 10 for the wire-wrapped and bare-bundle cases. Very similar cross-flow velocities are found for all four types of plane groups, indicating that the proposed momentum source model is adequate for representing the wire-wrap effects on swirl flow around the fuel pins. It is interesting to find that the sudden changes of the cross flow rates due to the wirewrap sweep through the planes were also slightly reproduced by the new momentum source model. Sinus distributions are found for all four groups, but the inner-planes (A and B) are subject to two incidents where the wire-wrap sweeps through the planes, while at the outer planes $(\mathrm{C}$ and $\mathrm{D})$ this happens once. At the inner planes, the coolant could flow both counterclockwise (positive cross velocity) and clockwise (negative cross velocity) with symmetry. However, a strong counter-clockwise flow occurs in the outer planes.

Since the applied momentum sources are dependent on local velocity, the magnitude adjusts automatically during the steady-state simulation, thus avoiding over-predicting the cross flow in the peripheral region. An example of the distribution of the introduced force is shown in Figure 11, in which the introduced force is much smaller in the upper left wire because the velocity inside is already very close to the wire tangential direction. 


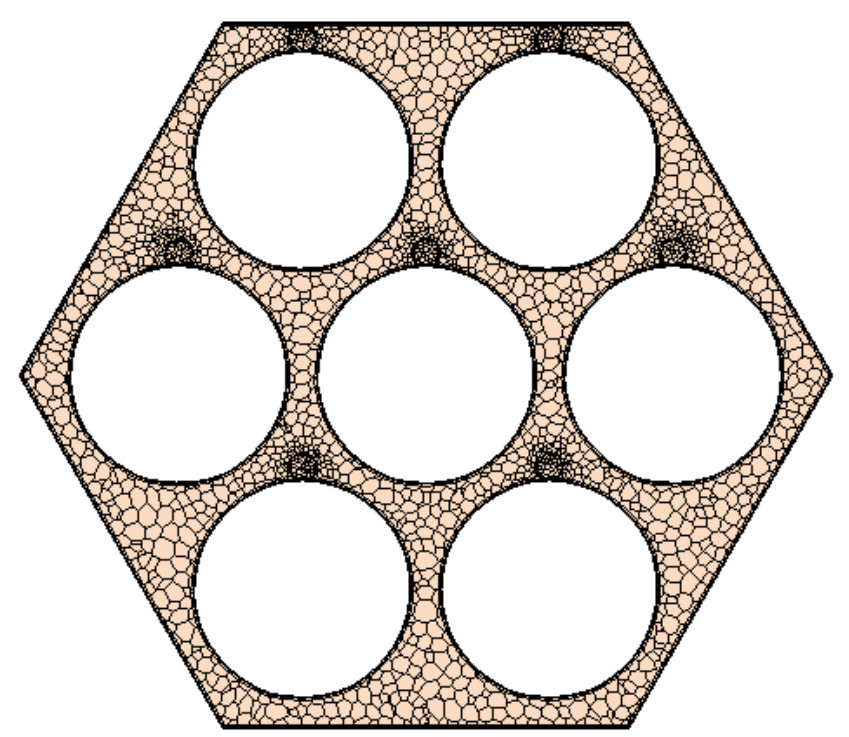

Figure 6: Mesh of a 7-pin bare bundle, wire surface conserved
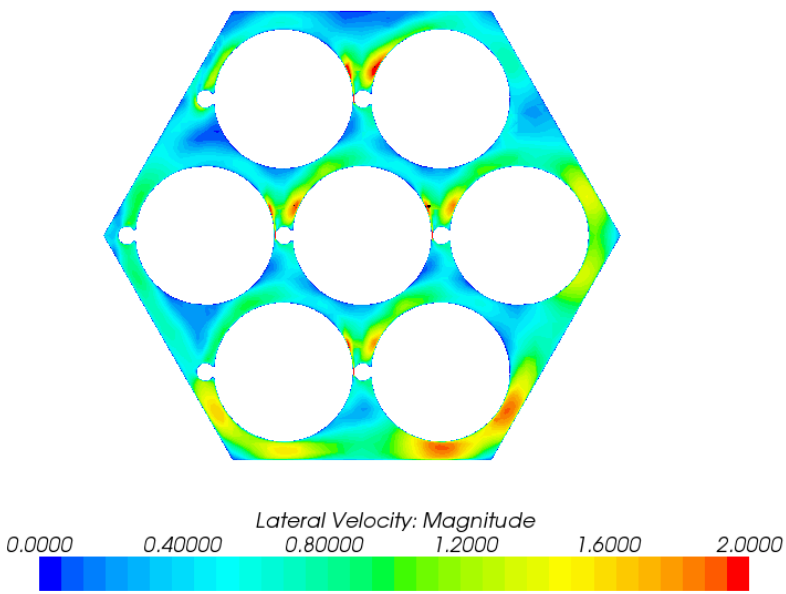

(a) Wire-wrapped bundle

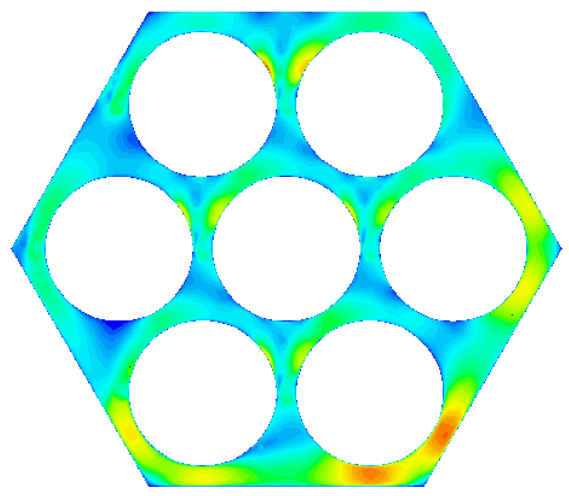

0.0000

Lateral Velocity: Magnitude 1.6203 2.0254 Figure 7: Lateral velocity distributions at the mid-span plane in 7-pin bundles 

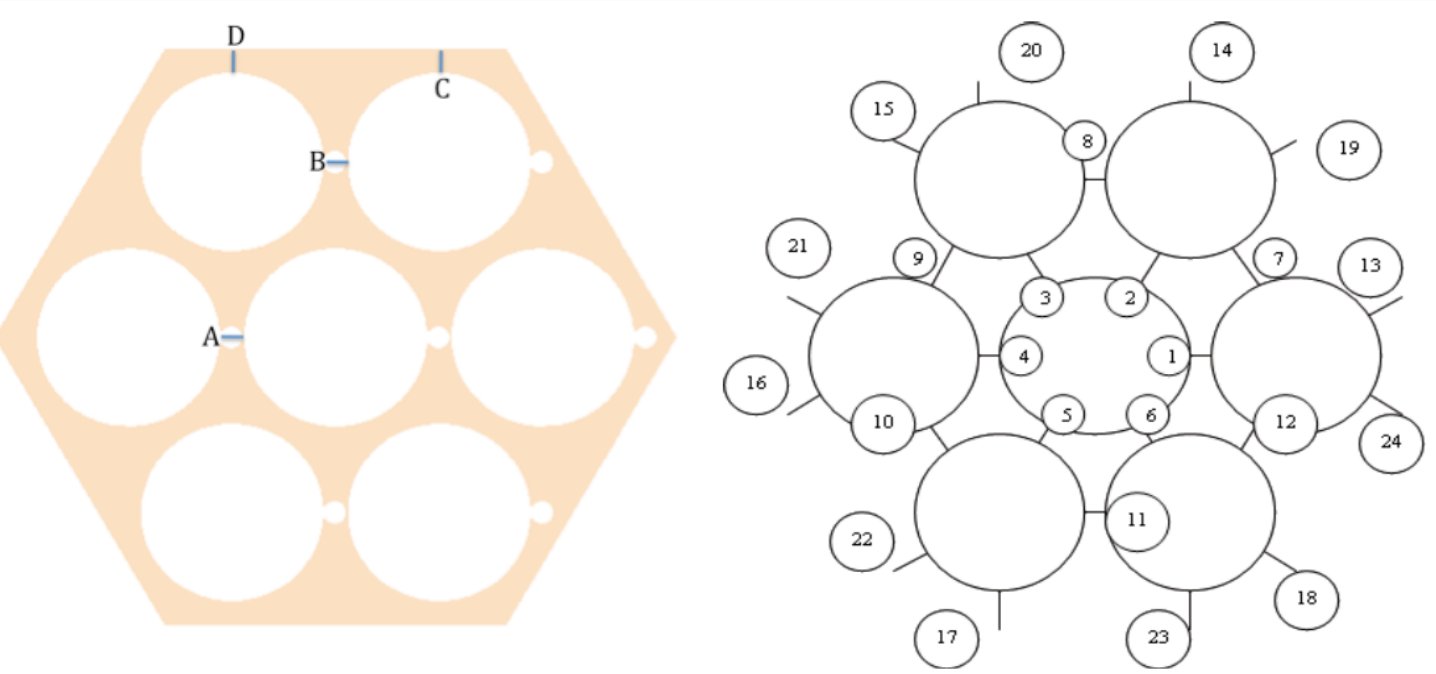

Figure 8: Geometry of the 7-pin wire-wrapped pin bundle; cut lines indicate planes and plane groups used for cross-flow comparisons (group A: plane 1-6; group B: plane 7-12; group C: plane 13-18; group D: plane 19-24. )

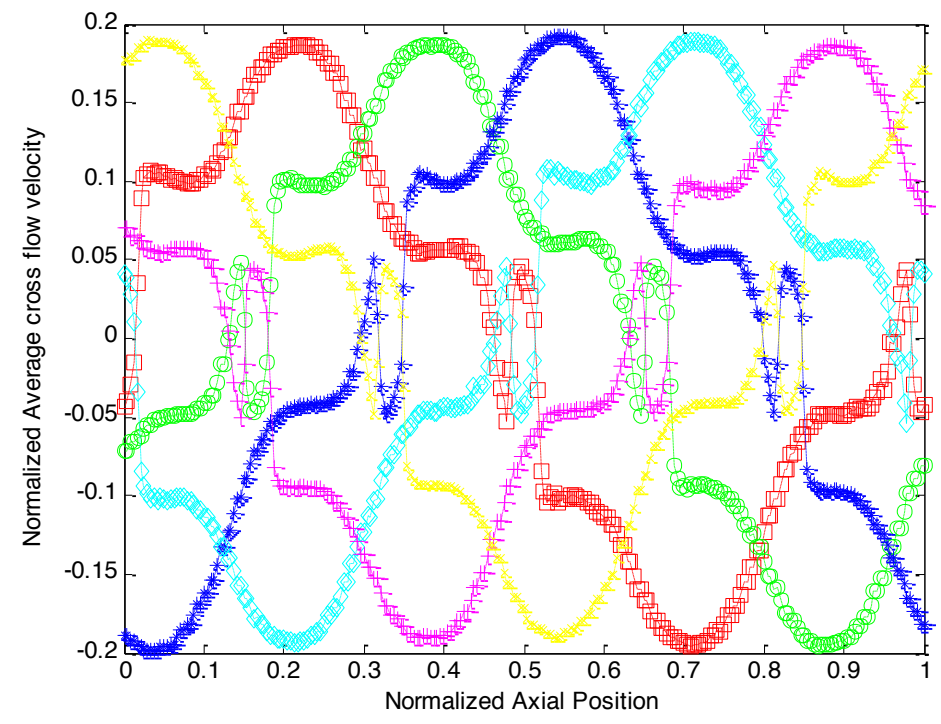

Figure 9: Cross flow velocity distributions for planes in group A, wire-wrapped bundle 


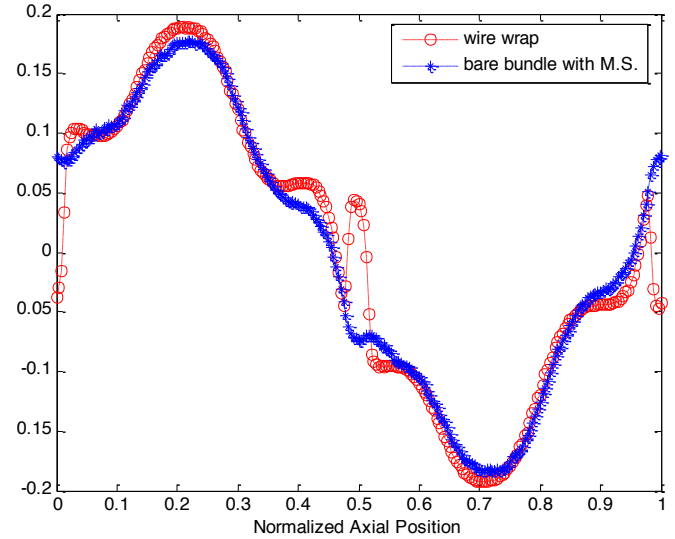

(a) Plane Group A

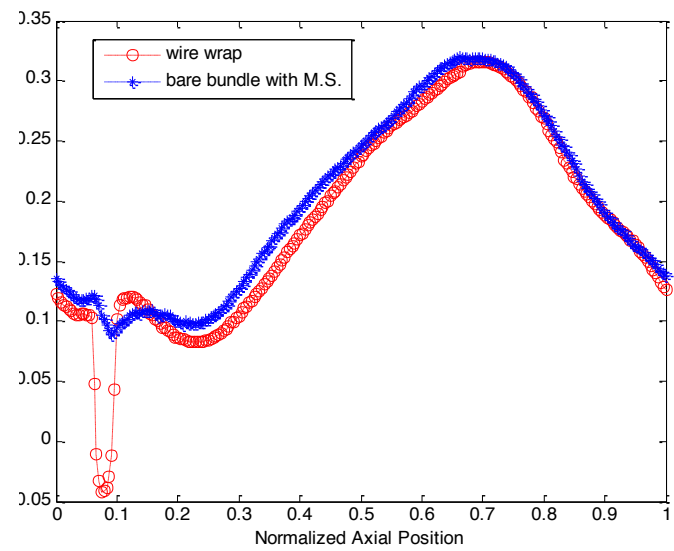

(c) Plane Group C

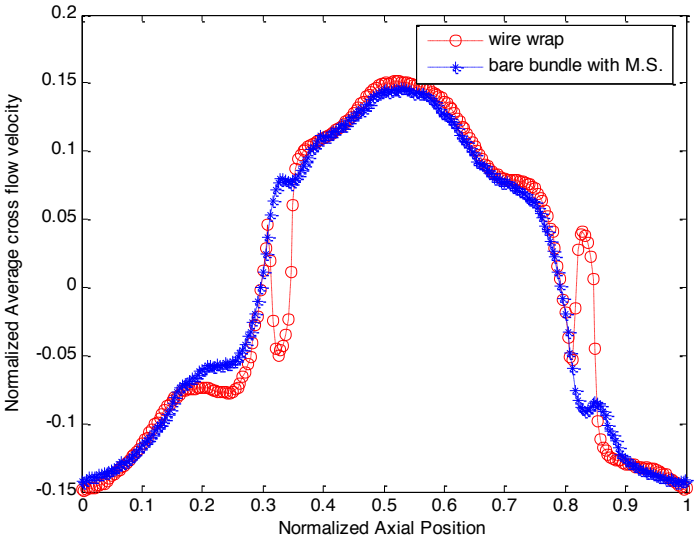

(b) Plane Group B

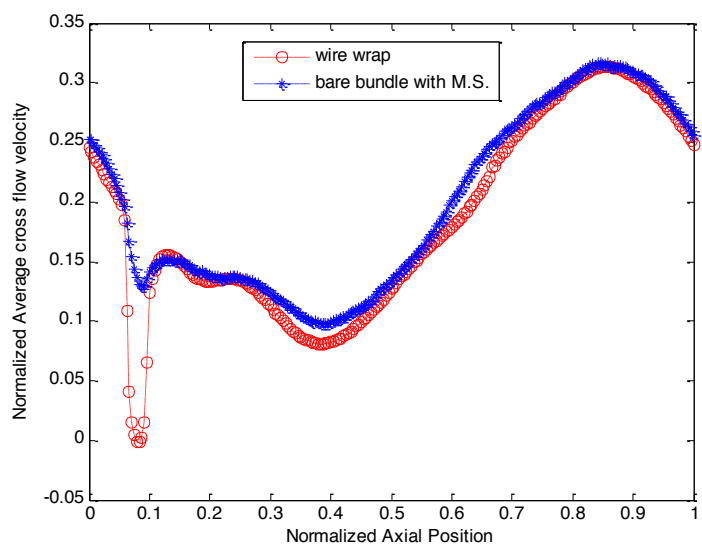

(d) Plane Group D

Figure 10: Comparison of inter-subchannel cross flow velocities

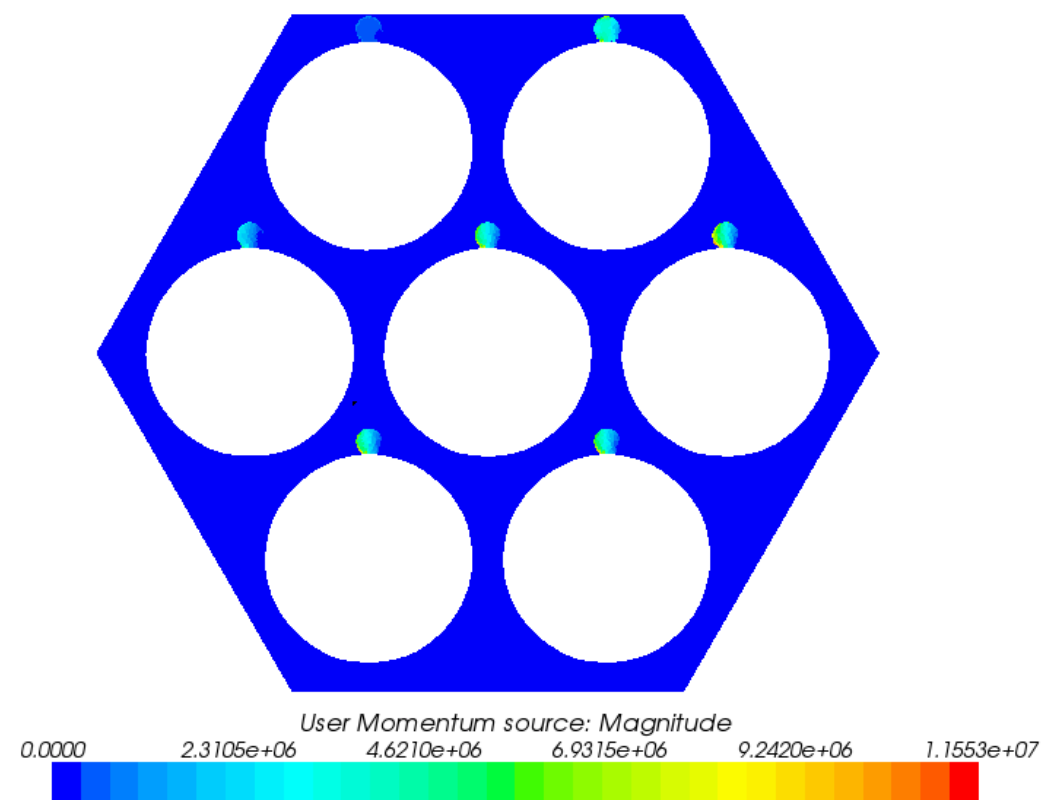

Figure 11: Momentum source distributions at $1 / 4$ span plane in a 7 -pin bare bundle 


\subsection{Mesh and Parameter Sensitivity Studies in 7-pin Bundle}

Additional simulations were conducted to examine the mesh and parameter effects of the momentum source model.

\subsubsection{Mesh effects}

As discussed in Section 3.2, to obtain an accurate MS affecting region, an in-place interface for the wire surface was added in the STAR-CCM+ model, which resulted in even higher mesh number than the wire-wrap case. To confirm the need of this modeling, another case was simulated with a relatively coarse mesh that did not conserve the wire-sweeping surface. The MS affecting region is shown in Figure 12. The lateral flow velocities are shown in Figure 13, and the pressure drops are listed in Table 1. Noted that the pressure drops were calculated from the plane-wise average pressures at the span inlet and outlet.

It is seen in Figure 12 that the MS affecting region is quite irregular if the mesh does not conserve the wire-sweeping surface. With a coarse mesh, the MS affecting region calculated from cell centroids will be larger than the actual wire-sweeping region. Thus, the resulting cross flow rates are enhanced at the peripheral planes, as shown in Figure 13 (c and d). Nonetheless, it is interesting to find that the cross flow rates at the inner planes are similar to those of the wire-wrapped bundle case. Similarly, the pressure drop of the MS with no wiresurface case is higher than the other two cases, as shown in Table 1.

An additional mesh sensitivity study was conducted by reducing the mesh cell number while conserving the wire surface. The cell number is reduced from two million (2007358, fine mesh), to $800 \mathrm{~K}$ (807581, coarse mesh 1), and to $470 \mathrm{~K}$ (470132, coarse mesh 2). The predicted cross-flow velocities are very similar for each of the different meshes, as seen in Figure 14. It is concluded that if the wire outer-surface is conserved, the inter-subchannel cross flow rate is only slightly sensitive to the cell number.

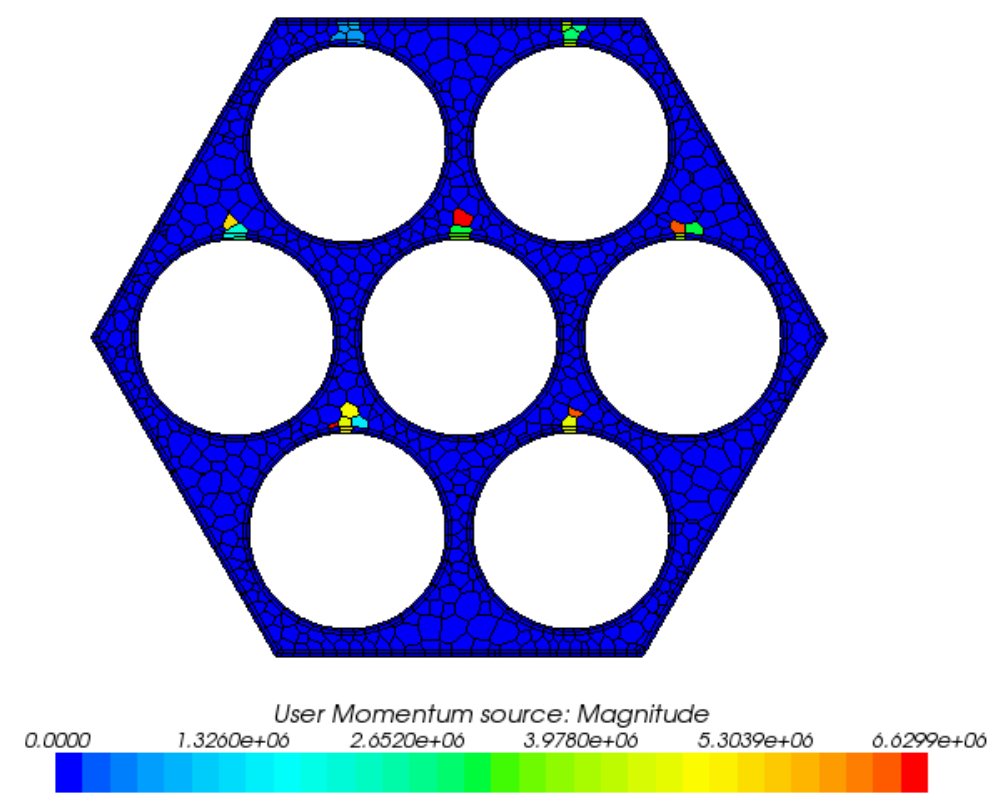

Figure 12: MS distributions at $1 / 4$ Span plane in a 7-pin bare bundle, without wire sweeping surface 


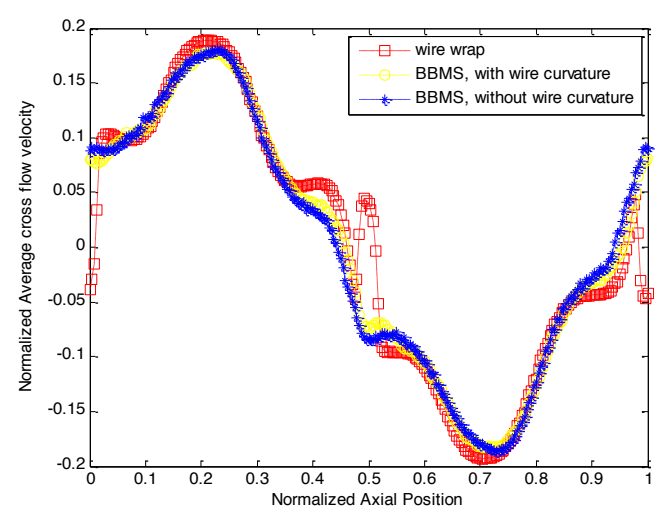

(a) Plane Group A

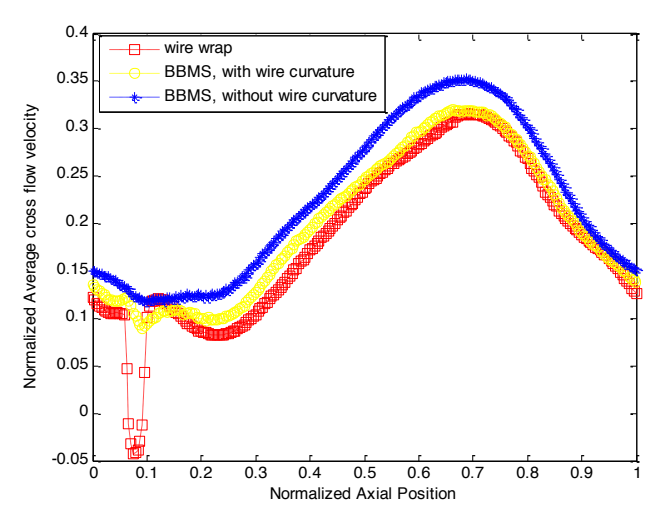

(c) Plane Group C

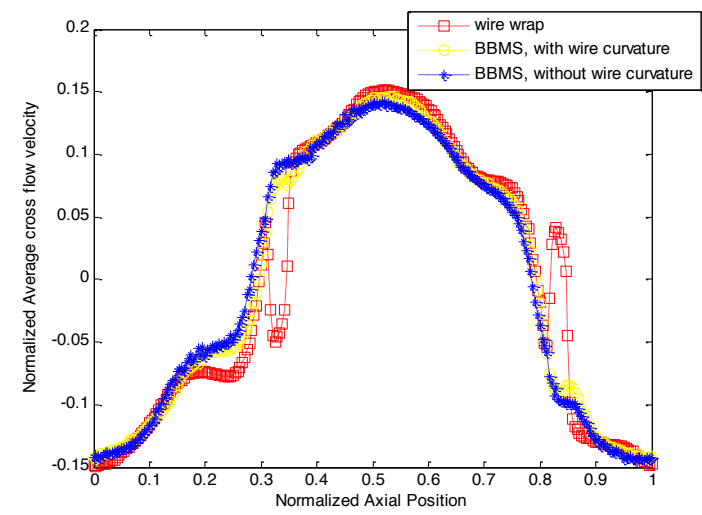

(b) Plane Group B

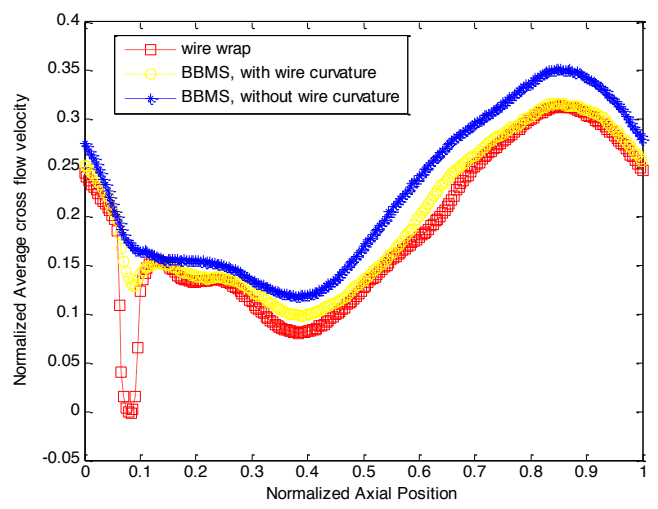

(d) Plane Group D

Figure 13: Inter-subchannel cross flow velocities, effects of wire sweeping surface

Table 1: Pressure drop comparison, effects of wire sweeping surface

\begin{tabular}{|l|c|c|c|}
\hline Case & $\begin{array}{c}\text { Wire-wrapped } \\
\text { bundle }\end{array}$ & $\begin{array}{c}\text { B.B. with M.S., } \\
\text { conserving wire } \\
\text { surface }\end{array}$ & $\begin{array}{c}\text { B.B. with M.S., } \\
\text { without conserving } \\
\text { wire surface }\end{array}$ \\
\hline Pressure drop $(\mathrm{kPa})$ & 15.61 & 15.76 & 16.86 \\
\hline
\end{tabular}




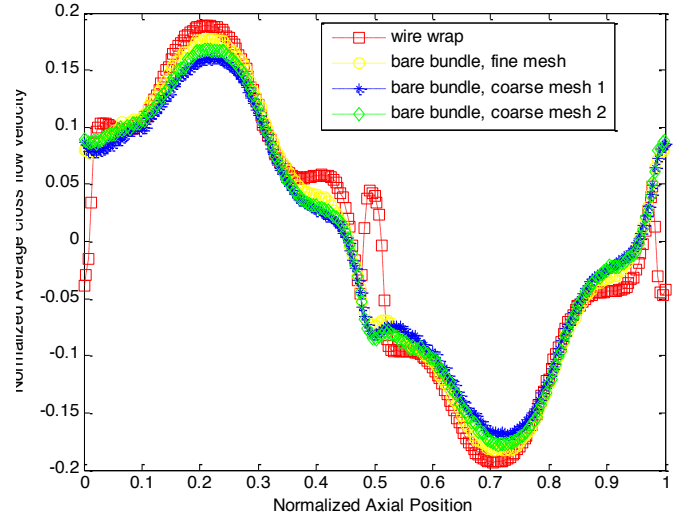

(a) Plane Group A

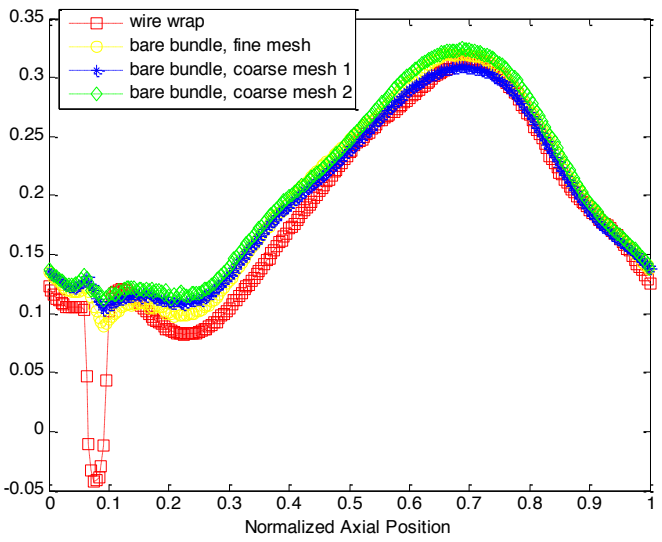

(c) Plane Group C

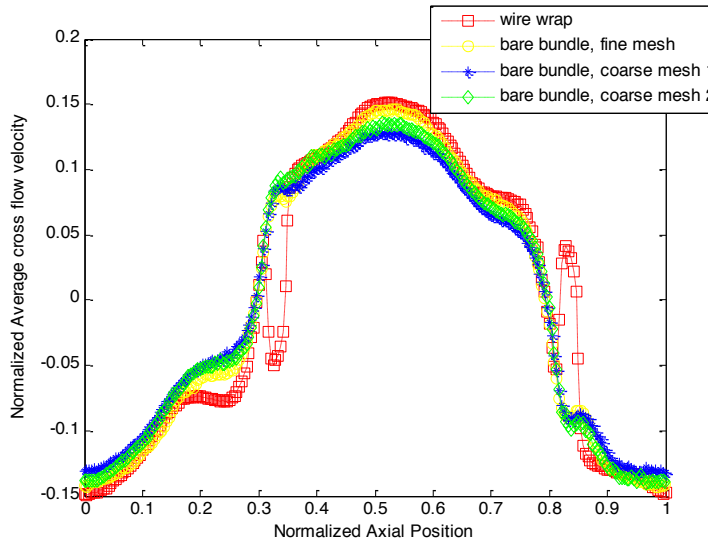

(b) Plane Group B

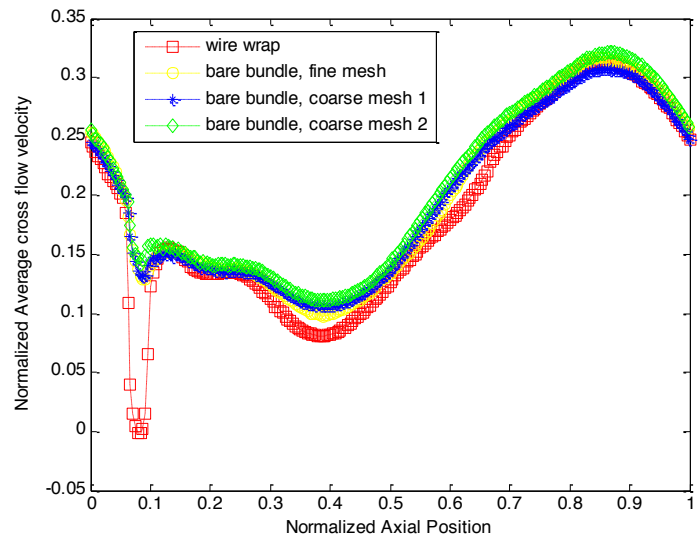

(d) Plane Group D

Figure 14: Inter-subchannel cross flow velocities, effects of mesh cell number

Table 2: Pressure drop comparison, effects of mesh cell number

\begin{tabular}{|l|c|c|c|c|}
\hline Case & $\begin{array}{c}\text { Wire- } \\
\text { wrapped } \\
\text { bundle }\end{array}$ & $\begin{array}{c}\text { B.B. with } \\
\text { M.S., fine } \\
\text { mesh }\end{array}$ & $\begin{array}{c}\text { B.B. with } \\
\text { M.S., coarse } \\
\text { mesh 1 }\end{array}$ & $\begin{array}{c}\text { B.B. with } \\
\text { M.S., coarse } \\
\text { mesh 2 }\end{array}$ \\
\hline Pressure drop $(\mathrm{kPa})$ & 15.61 & 15.76 & 15.21 & 15.31 \\
\hline
\end{tabular}

\subsubsection{The effect of the tangential force}

As discussion in Section 3.1, a force is introduced in the wire tangential direction to simulate the friction effects by the wire-wrap. It is of interest to investigate its effect on the cross-flow rates and pressure drop since it is modeled with a simple friction correlation.

A new simulation without the wire tangential force was conducted and compared with the full momentum source model. The inter-subchannel cross-flow velocities are shown in Figure 15, and the pressure drops are shown in Table 3. It is seen in Figure 15 that the force in the wire tangential direction only has minor effects on reducing cross flow rates. More significant 
effects are observed that contribute to pressure drop. Pressure drop reduces from 15.76 to $14.79 \mathrm{kPa}$ when the tangential force is excluded.

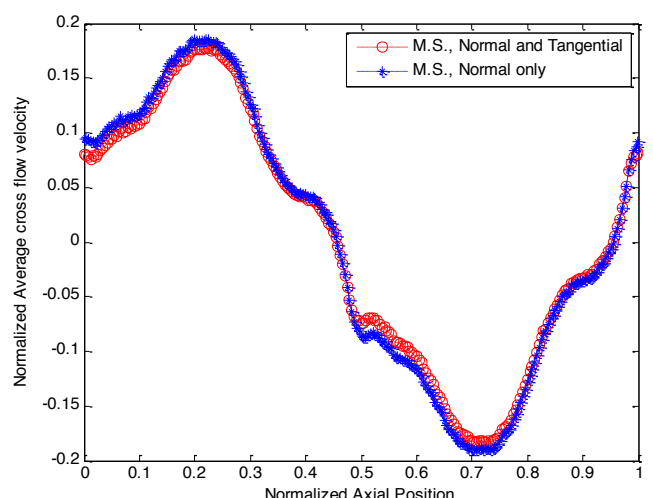

(a) Plane Group A

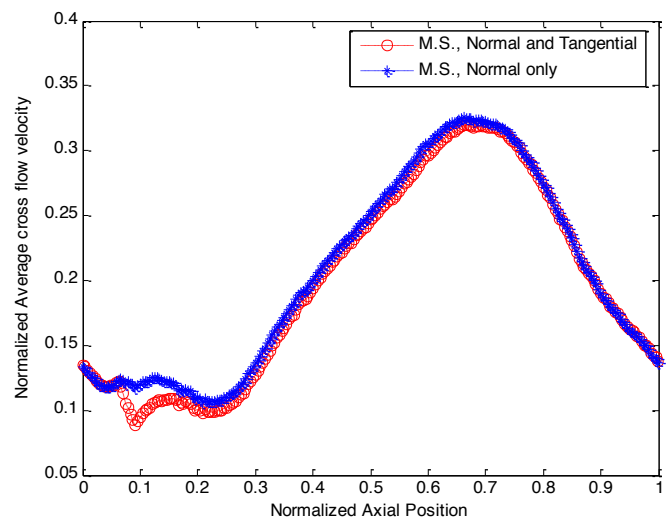

(c) Plane Group C

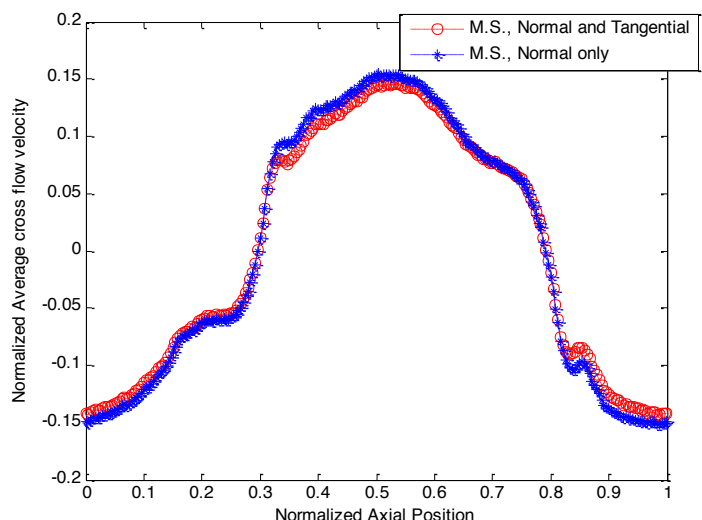

(b) Plane Group B

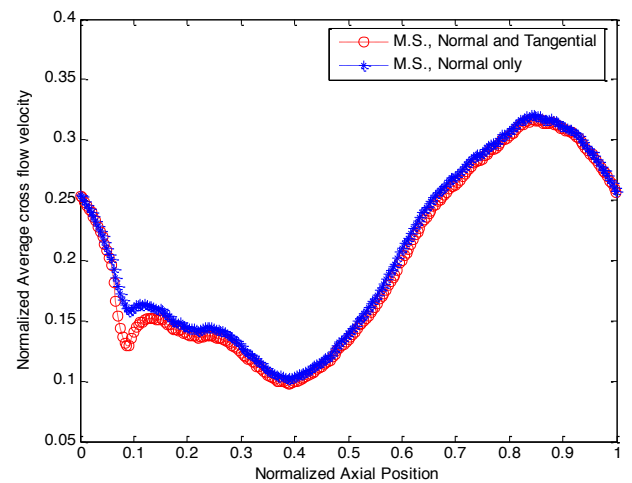

(d) Plane Group D

Figure 15: Inter-subchannel cross flow velocities, tangential force effect

Table 3: Pressure drop comparison among various momentum source models

\begin{tabular}{|l|c|c|c|}
\hline Case & $\begin{array}{c}\text { Wire-wrapped } \\
\text { bundle }\end{array}$ & B.B. with M.S. & $\begin{array}{c}\text { B.B. with M.S., without } \\
\text { tangential force }\end{array}$ \\
\hline Pressure drop $(\mathrm{kPa})$ & 15.61 & 15.76 & 14.79 \\
\hline
\end{tabular}

\subsubsection{Velocity effects}

The MS model was derived from the N-S equations with very few assumptions, with the goal to be flow regime independent and to cover a wide range of operating conditions. Several different operating conditions were considered to evaluate the MS model with respect to flow regime.

The velocity effects on the amplitudes of the cross flow were first examined with the wirewrapped bundle. Flow in the 7-pin wire-wrapped bundle at four different Reynolds numbers 
$(56000,28000,5600,1120)$ were simulated in STAR-CCM+, representing normal operating condition (turbulent flow), reduced turbulent flow, laminar-turbulent transition flow, and laminar flow conditions respectively. It should be noted that the laminar flow model was used for the $\mathrm{Re}=1120$ case, and the realizable $k-\varepsilon$ turbulence model and the two-layer all-y+ wall formulation were applied to the other cases. The modeling choice of the laminar flow and laminar-turbulent transition flow conditions were verified with a comparative study of three models: laminar flow model, v2f $k-\varepsilon$ model, and realizable $\mathrm{k}-\varepsilon$ model.

For the laminar flow case $(\operatorname{Re}=1120)$, it was found in Figure 16 that the predictions of the normalized cross flow velocities from the v2f $k-\varepsilon$ model are consistent with the results from the laminar flow model; and the resulting turbulent kinetic energy is negligible. Thus, the flow is in laminar regime, and the standard realizable $k-\varepsilon$ two-layer model should not be used. For laminar-turbulent transition flow case $(\mathrm{Re}=5600)$, the realizable $k-\varepsilon$ and the v2f model predicted similar cross flow velocities, as seen in Figure 17. However, the realizable $k$ $\varepsilon$ turbulent model should be used because: 1) the v2f model resulted in higher turbulent kinetic energy although it was intended for flow with small turbulence; and 2) the v2f model did not converge as well as the realizable $k$ - $\varepsilon$ two-layer model.

The resulting cross flow velocities in the wire-wrapped bundle cases were normalized and are shown in Figure 18. Similar distributions were found for all different flow conditions, indicating that the normalized cross flow is dominantly dependent on the bundle geometry, not the flow regime. In Figure 19, the cross flow velocities of the bare bundle with MS cases are compared with the results of the wire-wrapped bundle cases. For most flow regimes, the results confirm that the cross flow velocities match well between the two modeling approaches, indicating that the MS model is valid for a wide range of operating conditions without adjusting any modeling parameters. However, the model did not work as well under laminar flow conditions. Nonetheless, it should not be an opposing factor for the application of the model, since during low flow conditions, energy exchange due to the cross flow is likely to be negligible comparing to conduction. Thus, the accuracy of the cross flow prediction is not expected to be critical to reactor safety. This issue will be revisited once an intermediate-fidelity method is established. 

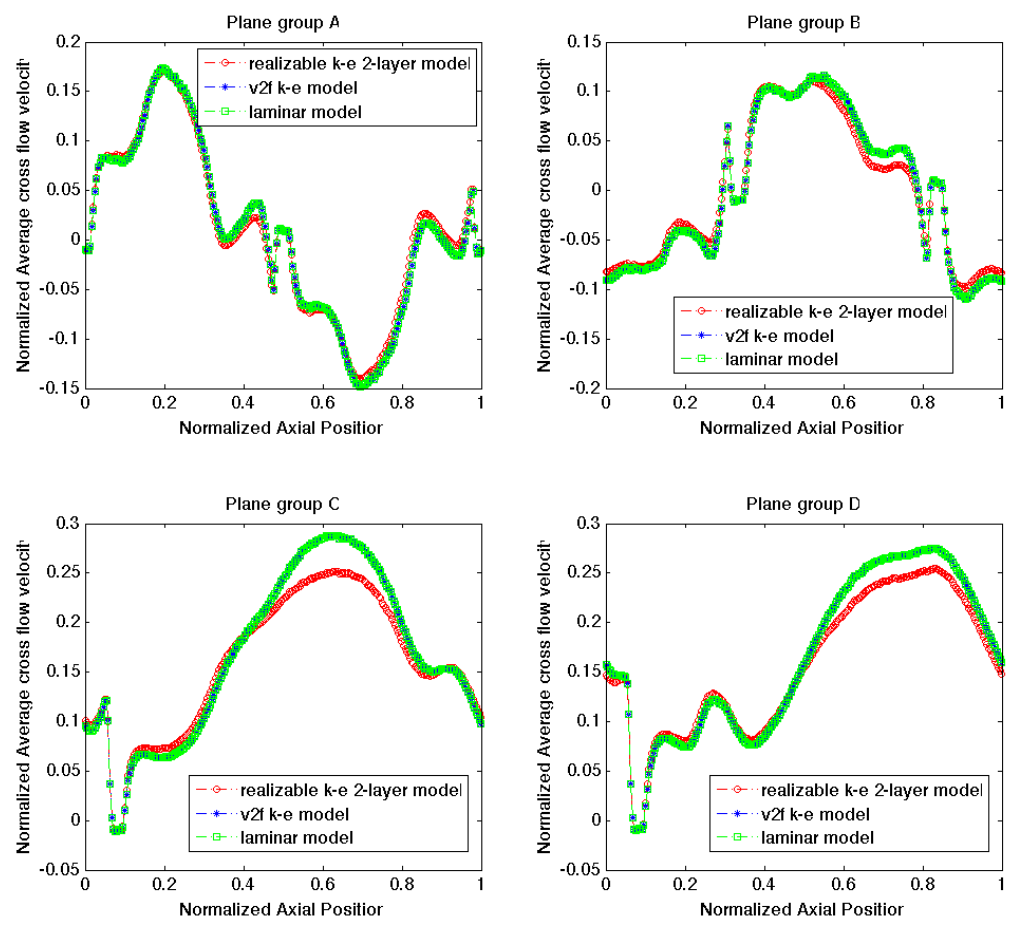

Figure 16: Cross flow velocities in wire-wrapped bundle, model effects at $\operatorname{Re}=1120$
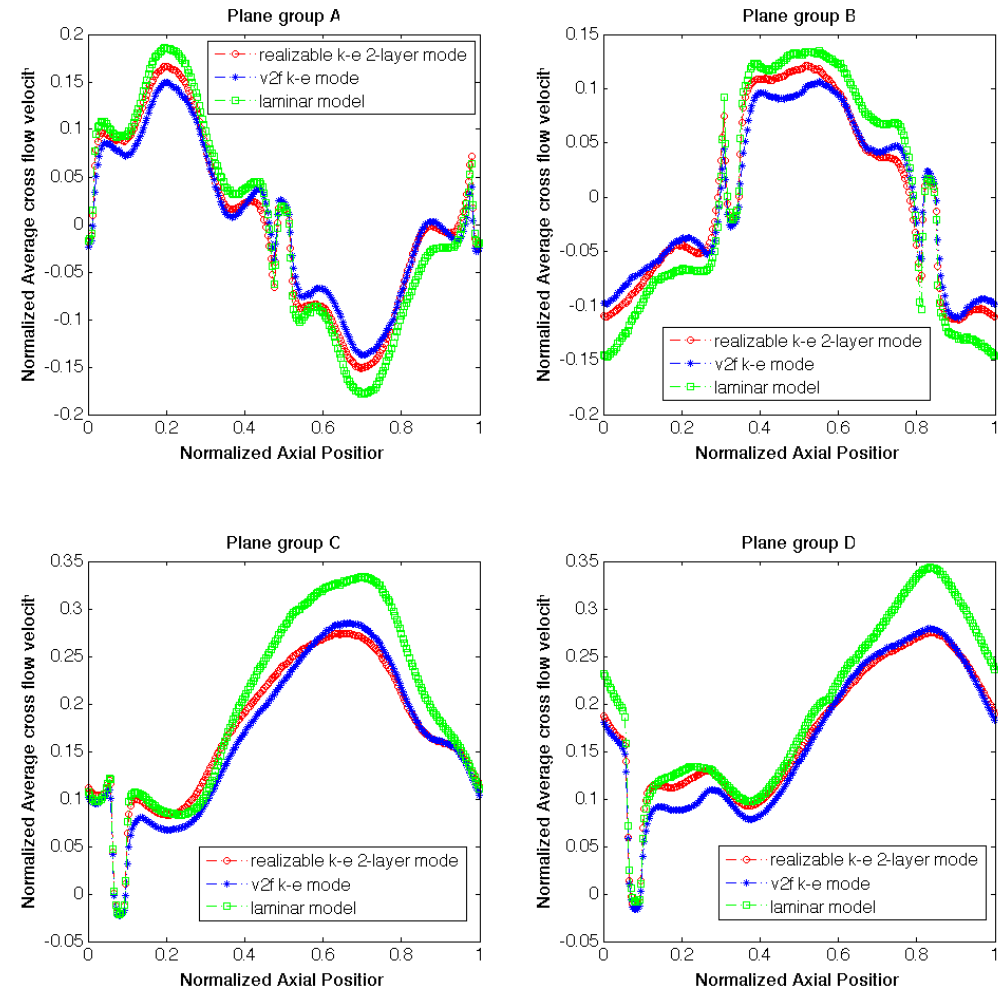

Figure 17: Cross flow velocities in wire-wrapped bundle, model effects of at $\mathrm{Re}=5600$ 

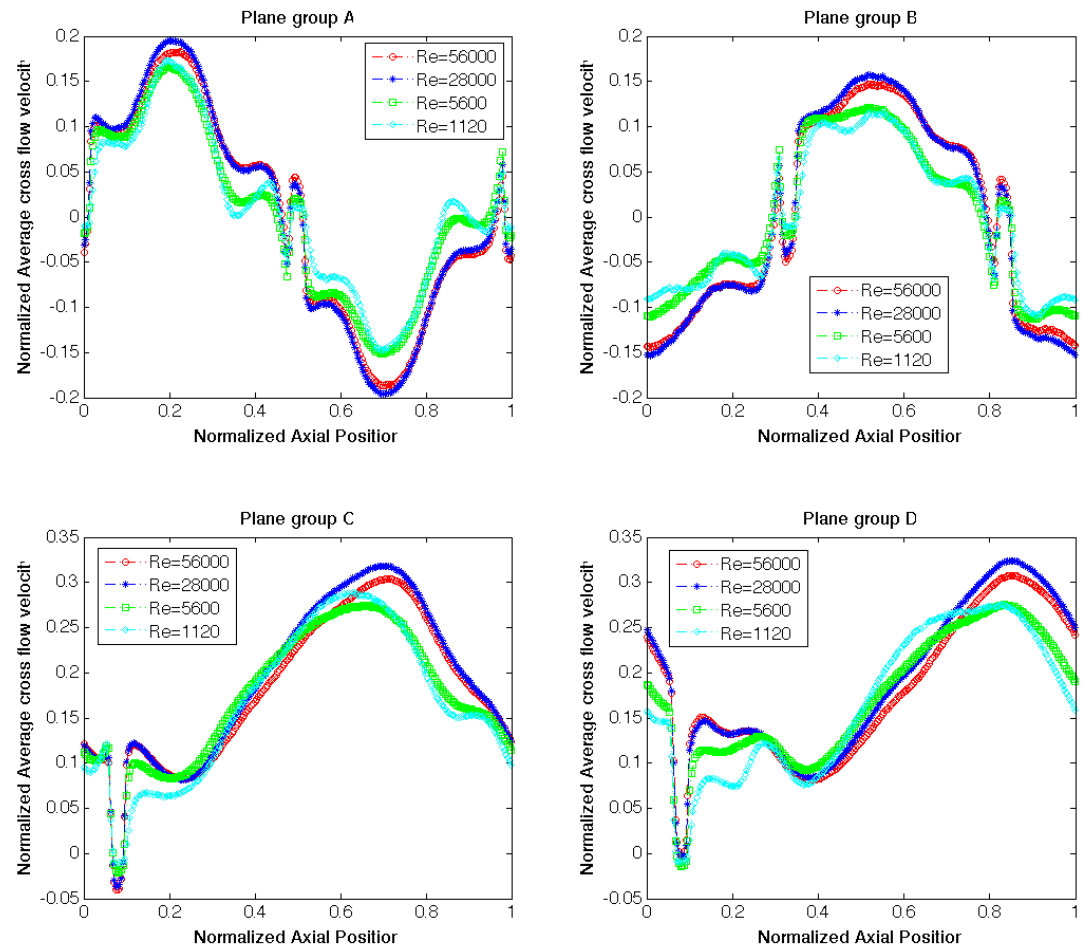

Figure 18: Cross flow velocities in wire-wrapped bundle, effects of Reynolds number
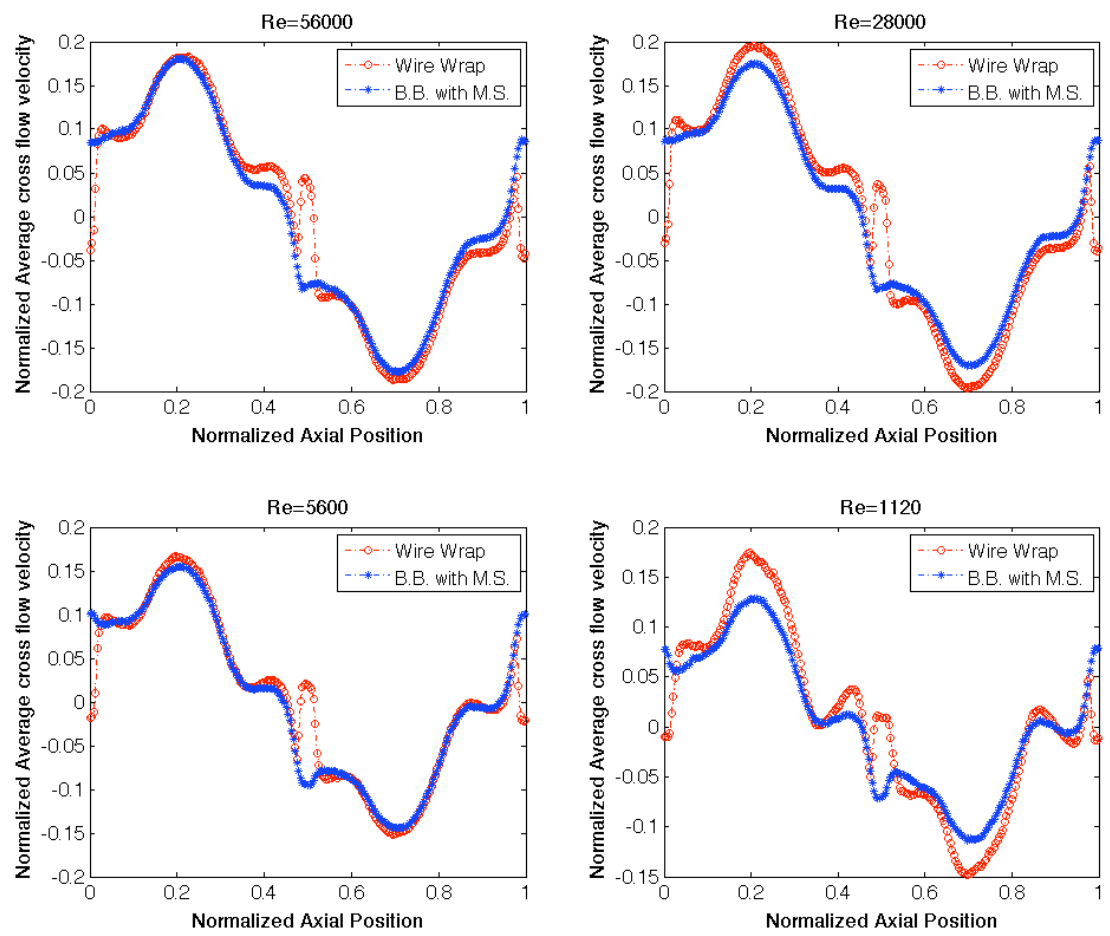

Figure 19: Cross flow velocities in wire-wrapped and B.B. with M.S. cases, velocity effects 


\subsection{7-pin Bundle Simulations}

To further examine the validity of the momentum source model described in Section 3.1, it is applied to a larger 37-pin bundle. For comparison, both the wire-wrapped pin bundle and the bare bundle with momentum source were simulated. The same models and boundary conditions used in the 7-pin bundle are applied.

A relatively coarse polyhedral mesh was used for the 37-pin wire-wrapped bundle, as shown in Figure 20. Again, average cross-flow velocities (normalized to the inlet velocity) were calculated as a function of axial position along the inter-subchannel planes for different types of plane groups shown in Figure 20.
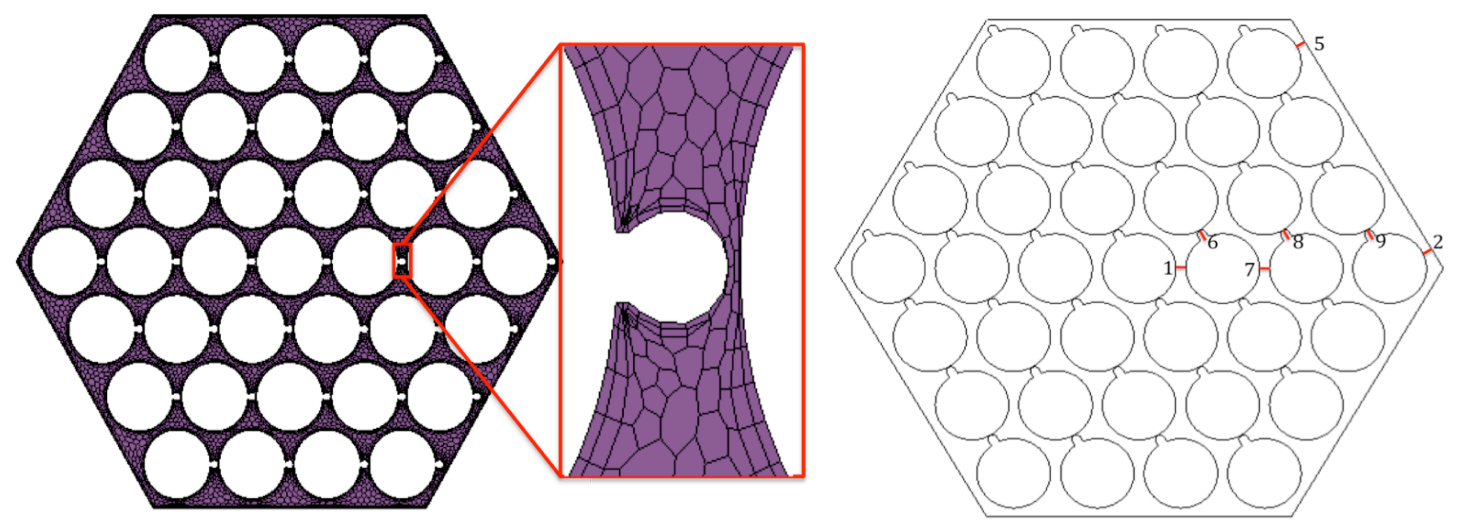

Figure 20: Mesh of a 37-pin wire-wrapped bundle in STAR-CCM+; cut lines indicate intersubchannel plane groups

For the wire-wrapped pin bundle, the cross flow velocity distributions for planes in inner groups are shown in Figure 21, while the outer plane groups are shown in Figure 22. Similar distributions are found as those in the 7-pin wire-wrapped bundle. However, it is interesting to note that the magnitude of the sinusoid distribution of the cross-flow velocities gradually reduces when moving from central planes to outer planes $(1 \rightarrow 6 \rightarrow 7 \rightarrow 8 \rightarrow 9)$, possibly due to the weaker wall effects for the inner planes.

For the 37-pin bare bundle case, an in-place interface for the wire surface was also added in the STAR-CCM+ mesh to obtain an accurate MS affecting region, as shown in Figure 23. The calculated cross flow velocity distributions are shown in Figure 24 for inner plane groups, and in Figure 25 for outer plane groups. The same tendency of reduced cross-flow rates from central to outer planes was observed. The inter-subchannel cross flow velocities for 4 typical plane groups are compared between the wire-wrapped and bare-bundle cases and is shown in Figure 26. The cross-flow distributions matched very well between the two cases for the four selected plane groups, indicating that the proposed momentum source model is also suitable for a 37-pin bundle. 


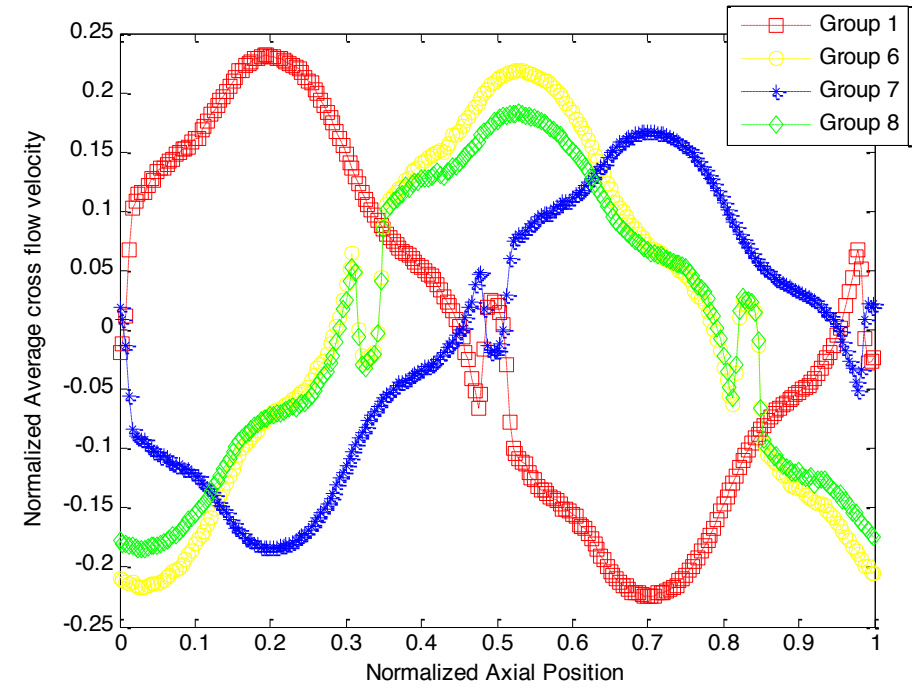

Figure 21: Averaged cross flow velocities in the 37-pin wire-wrapped bundle, inner plane groups

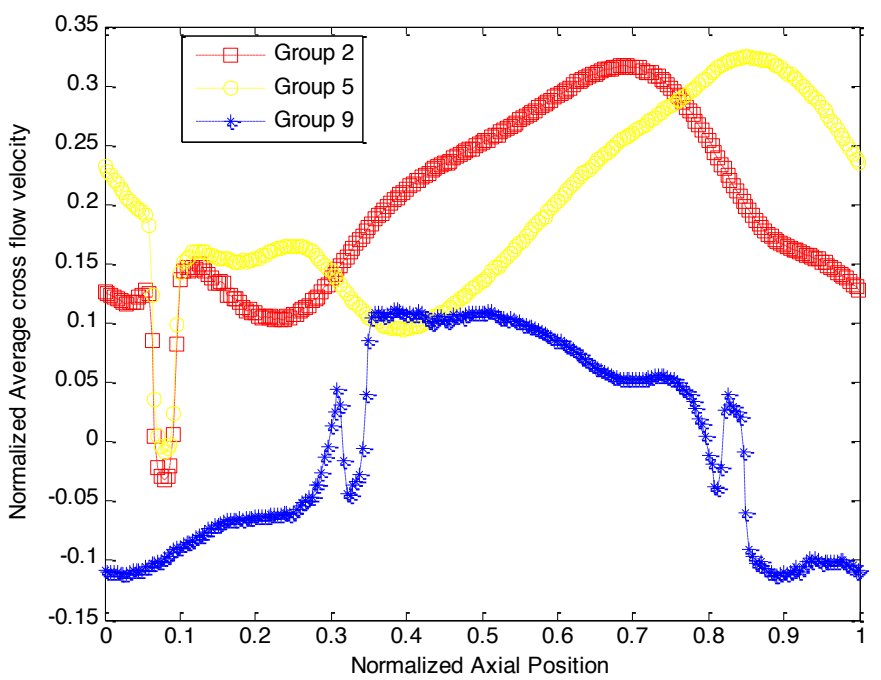

Figure 22: Averaged cross flow velocities in the 37-pin wire-wrapped bundle, outer plane groups 


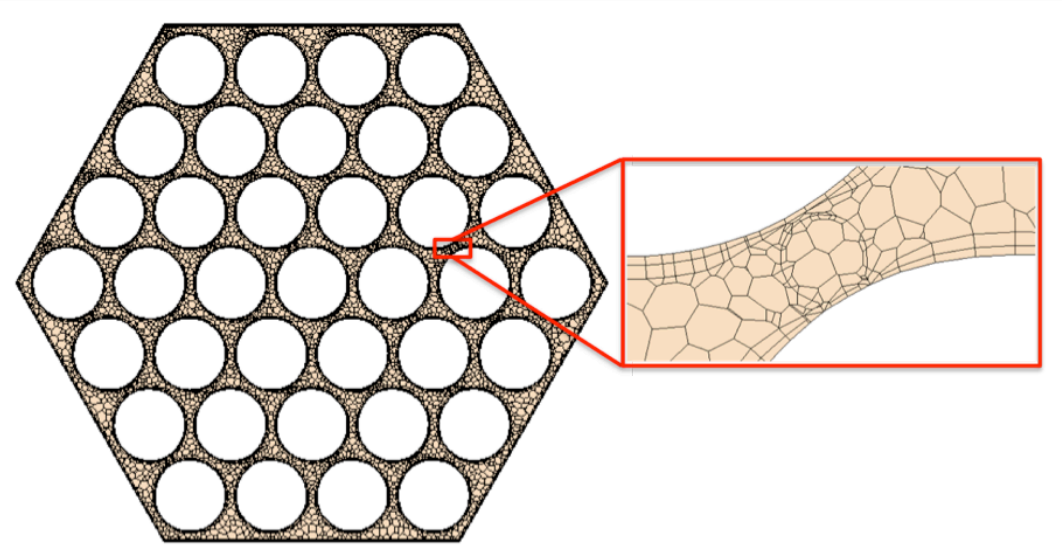

Figure 23: Mesh of a 37-pin bare bundle, wire surface conserved

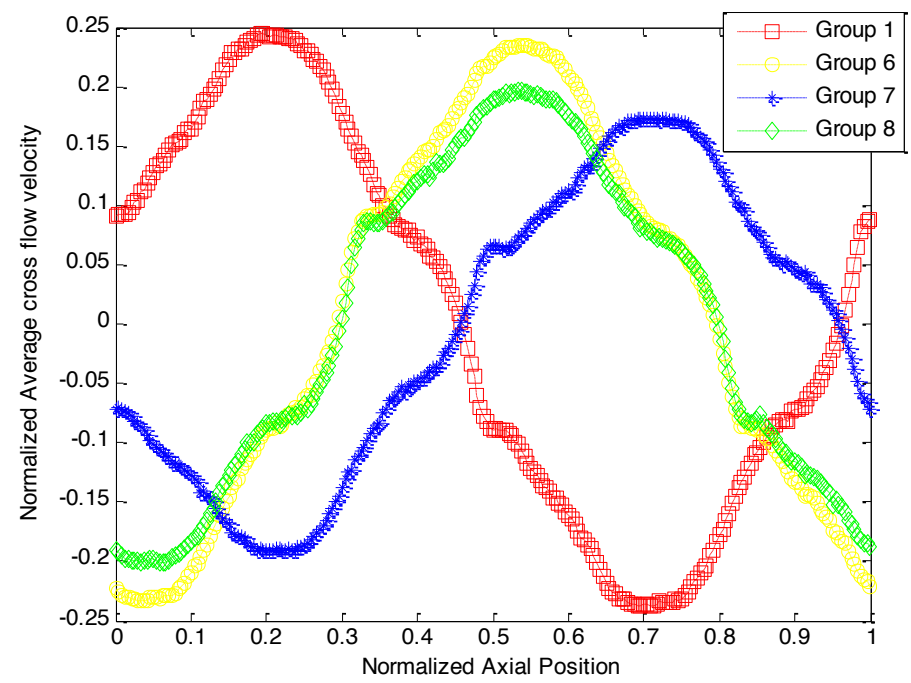

Figure 24: Averaged cross flow velocities in the 37-pin bare bundle with MS, inner plane groups 


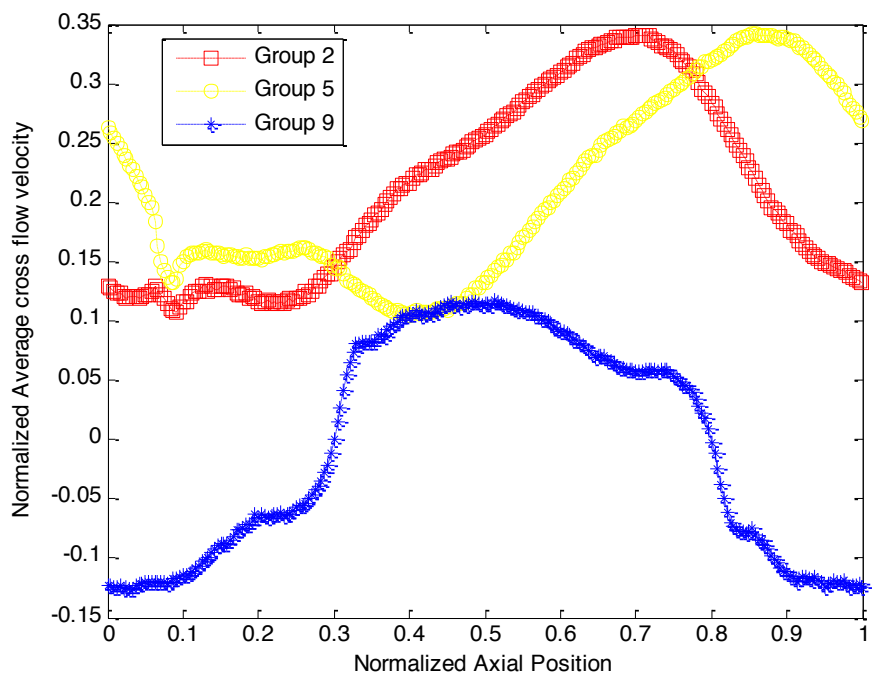

Figure 25: Averaged cross flow velocities in the 37-pin bare bundle with MS, outer plane groups

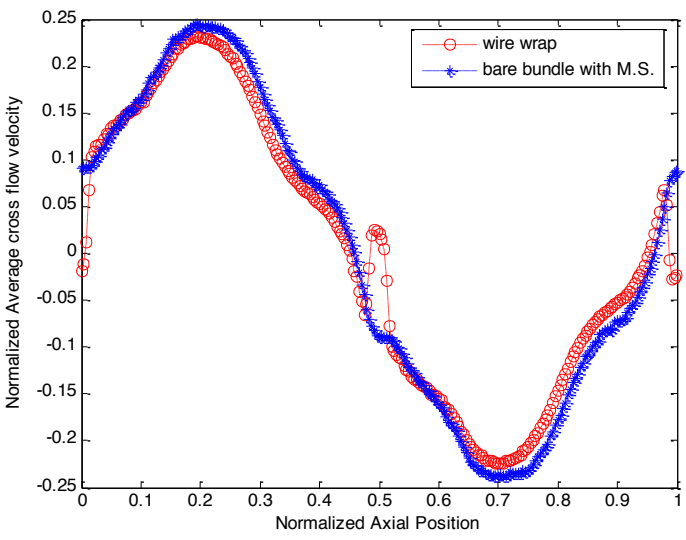

(a) Plane Group 1

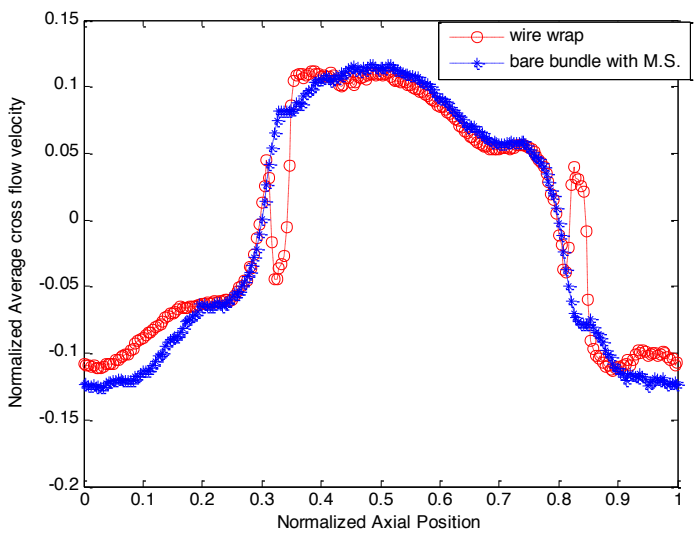

(c) Plane Group 9

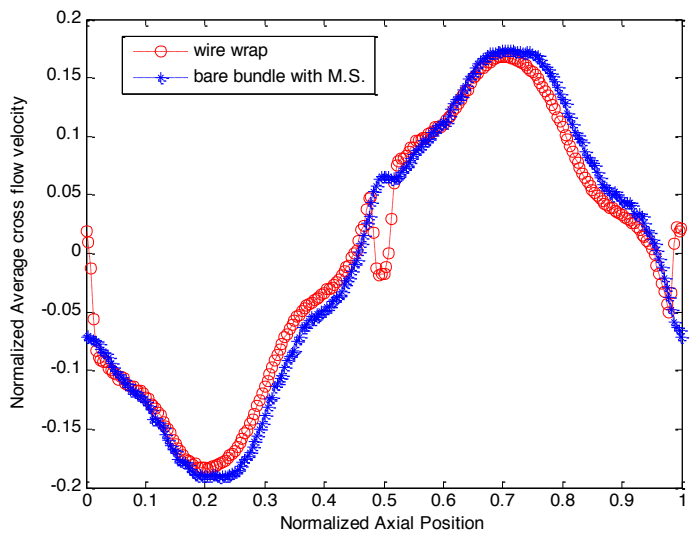

(b) Plane Group 7

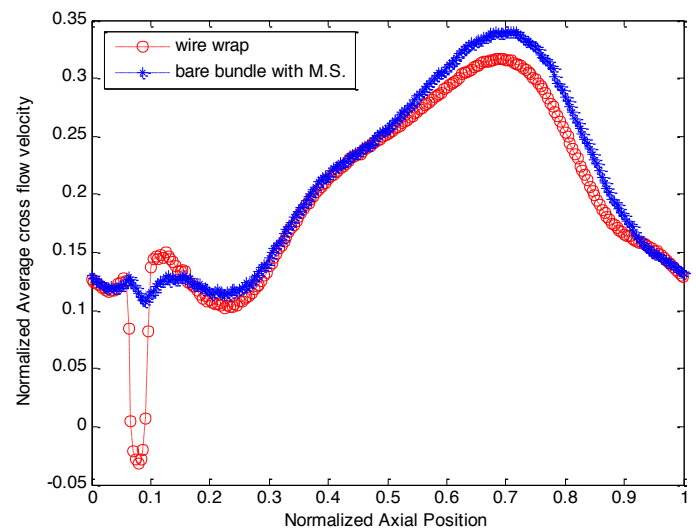

(d) Plane Group 2

Figure 26: Inter-subchannel cross flow velocities in 37-pin bundles 


\section{Summary}

This report summarizes the initial effort on the development of the intermediate-fidelity full assembly modeling method, aimed at providing full-core transient modeling capability when coupled to existing or emerging neutronics and fuel performance models. The requirements and the desired merits have been defined. A three-dimensional momentum source model has been developed to model the anisotropic flow in the complex flow channel without resolving the geometric details.

The momentum source model has been examined in both 7-pin and 37-pin bundle configurations by using the commercial CFD code STAR-CCM+ to simulate both wirewrapped and bare bundle geometries with momentum sources applied. It is shown that the momentum source model works well if its affecting region is accurately imposed. The calculated inter-subchannel flow velocities match very well between the bare bundle and wire-wrapped bundle cases. The validity of the model is further confirmed by mesh and parameter sensitivity studies. Moreover, the model is valid among a wide range of operating conditions, from laminar-turbulent transition flow to high Reynolds number turbulent flow. Because the momentum source model was derived from momentum conservation equations and depends only on local velocity profiles, it is expected that it can be applied to any wirewrapped bundle geometries and any flow regimes. It is also expected that the modeling strategy can be applied to other conditions with complex or distorted geometry, such as flow in blocked channels.

Further investigation on the intermediate-fidelity full assembly analysis method will be focused on developing improved models for natural turbulent mixing in bare and wirewrapped bundles, verification and validation of the developed models, the developing strategy and the implementation of the intermediate-fidelity code.

\section{References}

[1] A. Siegel, T. Tautges, A. Caceres, D. Kaushik, and P. Fischer, "Software Design of SHARP," Proc. Joint Int'l Topical Mtg. on Mathematics \& Computation and Supercomputing in Nuclear Applications, Monterey, California, April 15-19, 2007.

[2] W.D. Pointer, P. Fischer, A. Siegel and J. Smith, "RANS-based CFD Simulations of Wire- Wrapped Fast Reactor Fuel Assemblies," Proceedings of ICAPP '08, Anaheim, CA (2008).

[3] W.D. Pointer, J.W. Thomas, T.H. Fanning, et al., "RANS-Based CFD Simulations of Sodium Fast Reactor Wire-Wrapped Pin Bundles," Proceedings of $M \& C 2009$, Saratoga Springs, New York (2009).

[4] T.H. Fanning, W.D. Pointer, and J.W. Thomas, "Multi-Resolution Modeling of Subassembly Pin Bundles for Advanced Fast Reactor Safety Simulations," Proceedings of M\&C 2009, Saratoga Springs, New York (2009).

[5] G.D. Sjaardema, T.J. Tautges, T.J. Wilson, S.J. Owen, T.D. Blacker, W.J. Bohnhoff, T.L. Edwards, J.R. Hipp, R.R. Lober, and S.A. Mitchell, "CUBIT mesh generation environment Volume 1: Users manual”, Sandia National Laboratories, May (1994). 
[6] H.Y. Jeong, K.S. Ha, Y.M. Kwon, Y.B. Lee, D. Hahn, "A dominant geometrical parameter affecting the turbulent mixing rate in rod bundles", International Journal of Heat and Mass Transfer, 50, 908-918,(2007)

[7] T. J. Tautges, J. A. Kraftcheck, B. M. Smith, H.J. Kim, "Mesh-Oriented datABase (MOAB) Version 4.0 User's Guide", Argonne National Laboratory, (2011). www.mcs.anl.gov/ tautges/downloads/MOABv4-UG.pdf

[8] S. Balay, K. Buschelman, V. Eijkhout, W. Gropp, D. Kaushik, M. Knepley, L. Curfman McInnes, B. Smith, and H. Zhang, "PETSc Users Manual, Revision 3.1", Argonne National Laboratory, March (2010).

[9] F. E. Dunn, D. Hahn, H. Jeong, K Ha, and J. E. Cahalan, "Whole Core Sub-Channel Analysis for LMR Passive Safety Analysis," 14th Pacific Basin Nuclear Conference, Honolulu, Hawaii, March 21-25, (2004).

[10] K.L. Basehore, N.E. Todreas, "SUPERENERGY-2: A Multiassembly Steady-State Computer Code for LMFBR Core Thermal-hydraulic Analysis," PNL-3379. Pacific Northwest Laboratory, Richland, WA, (1980).

[11] C.W. Stewart, C.L. Wheeler, R.J. Cena, et al., "COBRA-IV: the Model and the Method," BNWL-2214, Pacific Northwest Laboratory, (1979).

[12] H. Ninokata, A. Efthimiadis, N.E. Todreas, "Distributed resistance modeling of wirewrapped rod bundles," Nucl. Eng. Des. 104, 93-102, (1987).

[13] H.Y. Jeong, K. S. Ha, W.P Chang, et al., "Modeling of flow blockage in a liquid metal-cooled reactor subassembly with a subchannel analysis code," Nucl. Technol. 149 (1), 71-87,(2005).

[14] R. Gajapathy, et al., "A comparative CFD investigation of helical wire-wrapped 7, 19 and 37 fuel pin bundles and its extendibility to 217 pin bundle," Nuclear Engineering and Design, 239, 2279-2292, (2009).

[15] K. Natesan, et al., "Turbulent flow simulation in a wire-wrap rod bundle of an LMFBR,” Nuclear Engineering and Design, 240, 1063-1072, (2010).

[16] K.D. Hamman and R.A. Berry, "A CFD simulation process for fast reactor fuel assemblies," Nuclear Engineering and Design, 240(9), 2304-2312, (2010).

[17] R. Hu and T.H. Fanning, "On the Modeling of Natural Turbulent Mixing in Wirewrapped Rod Bundles," 2011 American Nuclear Society Annual Meeting, Hollywood, Florida, (2011) (Accepted).

[18] CD-adapco Group, "STAR-CCM+ User Manual v5.09," Melville, NY (2010).

[19] N.E. Todreas and M.S. Kazimi, "Nuclear System I, Thermal Hydraulic Fundamentals", Hemisphere Publishing Corporation, (1990). 




\section{Argonne}

Nuclear Engineering Division

Argonne National Laboratory

9700 South Case Avenue

Argonne, IL 60439

www.anl.gov 